\title{
Druggable Transcriptional Networks in the Human Neurogenic Epigenome ${ }^{[\mathrm{S}}$
}

\author{
Gerald A. Higgins, Aaron M. Williams, Alex S. Ade, Hasan B. Alam, and Brian D. Athey \\ Departments of Computational Medicine and Bioinformatics (G.A.H., A.S.A., B.D.A.), Surgery (A.M.W., H.B.A.), and Psychiatry (B.D.A.), \\ University of Michigan Medical School, Ann Arbor, Michigan
}

Abstract............................................................. 520

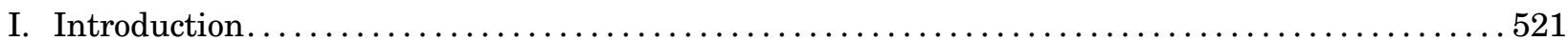

A. Master Regulators of Transcriptional Networks as Druggable Targets. . . . . . . . . . ... 521

B. The Functional Topology of the Three-Dimensional Spatial Genome ................. 522

1. Spatial Topology and Gene Regulation within the Chromatin Environment .........5 523

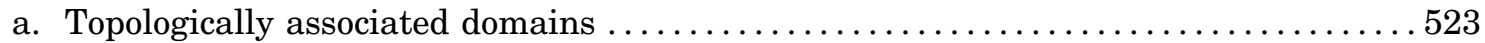

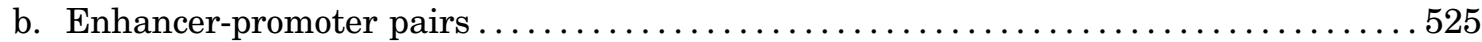

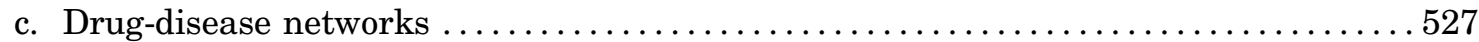

2. Neurogenic Transcriptional Mechanisms .............................. 528

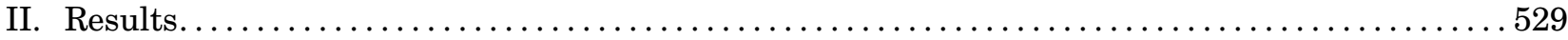

A. Characterization of Enhancer-Promoter Topologically Associated Domain Loops from

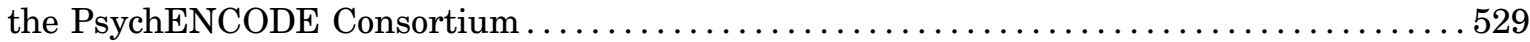

1. Control of Neurogenic Transcriptional Networks by Chromatin Remodeling

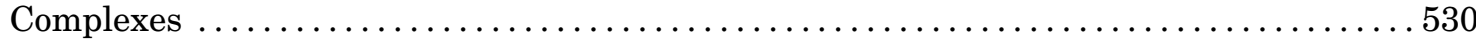

2. Network Analysis of Druggable Chromatin Remodeling and Neurogenic

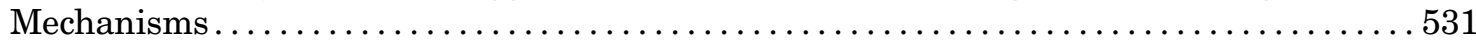

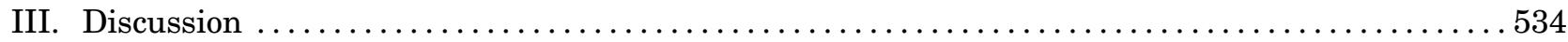

A. Emerging Trends in the Druggability of Transcriptional Regulatory Networks ......... 534

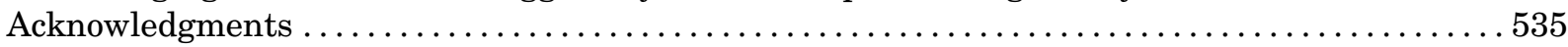

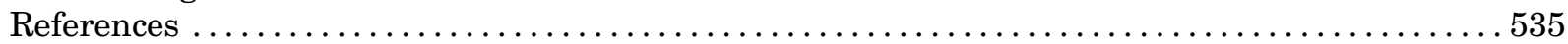

Abstract-Chromosome conformation capture methods have revealed the dynamics of genome architecture which is spatially organized into topologically associated domains, with gene regulation mediated by enhancer-promoter pairs in chromatin space. New evidence shows that endogenous hormones and several xenobiotics act within circumscribed topological domains of the spatial genome, impacting subsets of the chromatin contacts of enhancer-gene promoter pairs in cis and trans. Results from the National Institutes of Health-funded PsychENCODE project and the study of chromatin remodeling complexes have converged to provide a clearer understanding of the organization of the neurogenic epigenome in humans. Neuropsychiatric diseases, including schizophrenia, bipolar spectrum disorder, autism spectrum disorder, attention deficit hyperactivity disorder, and other neuropsychiatric disorders are significantly associated with mutations in neurogenic transcriptional networks. In this review, we have reanalyzed the results from publications of the PsychENCODE Consortium using pharmacoinformatics network analysis to better understand druggable targets that control neurogenic transcriptional networks. We found that valproic acid and other psychotropic drugs directly alter these networks, including chromatin remodeling complexes, transcription factors, and other epigenetic modifiers. We envision a new generation of CNS therapeutics targeted at neurogenic transcriptional control networks, including druggable parts of chromatin remodeling complexes and master transcription factorcontrolled pharmacogenomic networks. This may

Address correspondence to: Dr. Brian D. Athey, Department of Computational Medicine and Bioinformatics, University of Michigan Medical School, 100 Washtenaw Ave., Ann Arbor, MI 48109. E-mail: bleu@med.umich.edu

This work was supported by grants from the U.S. Army, Department of Defense [F046821,17-PAF00235, and F048322,16-PAF02030 to G.A.H., A.M.W., H.B.A.]; the Massey Foundation (G.A.H., A.M.W., H.B.A.); and National Institutes of Health National Institute of Diabetes and Digestive and Kidney Diseases [Grants P30 DK081943] and National Institute of General Medical Sciences [Grant T32 GM0704490552] to B.D.A.

https://doi.org/10.1124/pr.119.017681.

\$This article has supplemental material available at pharmrev.aspetjournals.org. 
provide a route to the modification of interconnected gene pathways impacted by disease in patients with neuropsychiatric and neurodegenerative disorders. Direct and indirect therapeutic strategies to modify the master regulators of neurogenic transcriptional control networks may ultimately help extend the life span of CNS neurons impacted by disease.

\section{Introduction}

Analysis of druggable targets within chromatin remodeling complexes and transcription factor pathways (Braun et al., 2017; Safe et al., 2018; Sievers et al., 2018), in conjunction with data from the PsychENCODE program funded by the National Institutes of Health (Akbarian et al., 2015), has contributed to a new era of drug discovery in neuropharmacology. This paradigm involves the therapeutic manipulation of developmental gene networks within the epigenome. Previous research has shown that 1) the majority of single nucleotide polymorphisms (SNPs) associated with human disease risk and drug response variability in genomewide association studies (GWAS) are located within noncoding enhancers that regulate gene expression (Maurano et al., 2012; Higgins et al., 2015a; Onengut-Gumuscu et al., 2015); 2) the threedimensional (3D) spatial environment of the neuronal genome is organized such that regulatory gene networks consist of enhancer-gene promoter chromatin loops located within topologically associated domains (TADs) (Rao et al., 2014; Matharu and Ahituv, 2015; Dekker and Mirny, 2016; Guo et al., 2017; de la TorreUbieta et al., 2018); and 3) mutations within genes that encode chromatin remodeling complexes and master transcription factors that drive the reprogramming of cell fate mediated by the regulatory epigenome are important determinants of etiology in human neurologic disease (Pohodich and Zoghbi, 2015; Berson et al., 2017; Li et al., 2017; Rajarajan et al., 2018). Furthermore, many psychotropic drugs, including antidepressants and antiepileptics such as valproic acid, act, in part, through induction of neurogenesis and neural developmental mechanisms (Chu et al., 2015; Miller and Hen, 2015; Walker et al., 2015; Nikolian et al., 2018).

Recent studies from the PsychENCODE Consortium have begun to characterize the dynamic nature of chromatin spatial interactions that control developmental patterns of gene regulation in human neural progenitor cells and in neuropsychiatric disease (de la Torre-Ubieta et al., 2018; Girdhar et al., 2018; Rajarajan et al., 2018). This research emphasizes the importance of the regulation of enhancer-promoter contacts in the chromatin interactome and developmental reprogramming of gene expression in the etiology of neuropsychiatric disease. Furthermore, it has revealed the relative persistence of TAD integrity during human brain development in the absence of brain pathology. In parallel, recent studies demonstrate that chromatin remodeling complexes involved in neural and disease development are the master regulators of targeted developmental gene programming, comprising ripe targets for drug discovery. They have even been described as analogous to "air traffic controllers" (Ronan et al., 2013; Staahl and Crabtree, 2013; Braun et al., 2017; Crabtree et al., 2018; Mashtalir et al., 2018). Together, these data provide a new understanding of the molecular basis of what were once thought to be obscure mechanisms of psychotropic drug action in human brain and causality in neuropsychiatric disease.

The objective of this review is to provide an overview of the functional topology of the spatial genome, including important druggable targets in the regulome and master regulators of transcriptional gene networks such as chromatin remodeling complexes and transcription factors, and to reassess the mechanisms of valproic acid and other psychotropic drugs using bioinformatics data analysis. This review will also provide a brief roadmap for a new generation of therapeutics that will directly alter transcriptional gene networks. Alongside gene transfer and genome editing-based therapeutics, new pharmaceuticals directed at the control of developmental epigenomic plasticity, including cell type-specific transcription factors, chromosome remodeling complexes, transcription factors and their networks, and regulatory RNAs, comprise one of the most innovative and promising domains of drug discovery in neuropharmacology (Allis and Jenuwein, 2016; Crabtree et al., 2018).

\section{A. Master Regulators of Transcriptional Networks as Druggable Targets}

CNS drug discovery has largely focused on individual protein targets whose functional properties may be altered using small chemical compounds with the goal of changing brain levels of well-characterized neurotransmitter systems, reducing inflammation and excitotoxicity in neurodegenerative disease, stopping

\footnotetext{
ABBREVIATIONS: AAV, adenovirus-associated virus vector; Cas9, CRISPR-associated protein 9; CRISPR, clustered regularly interspaced short palindromic repeats; CNS, central nervous system; CT, chromosome territory; CTCF, CCCTC-binding protein; eQTL, expression quantitative trait locus; GWAS, genomewide association studies; NIH, National Institutes of Health; nBAF, neural Brg/Brm-associated factor; npBAF, neural progenitor Brg/Brm-associated factor; PheWAS, phenome-wide association studies; PiRNA, "Piwi-interacting" or "PingPong" RNAs; SNP, single nucleotide polymorphism; TAD, topologically associated domain; TALEN, transcription activator-like effector nucleases; 3D, three dimensional; 4D, four dimensional.
} 
infection with anti-bacterial and anti-viral agents, removing pathologic protein deposits and prions, and related target strategies. However, even with the advent of intracellular inhibitors and monoclonal antibodybased drugs, widespread and varied off-target effects demonstrate that limiting drug discovery to single protein targets does not inhibit the emergence of unknown and sometimes devastating adverse drug events caused by pharmacodynamic substrates. Until recently it has been assumed that extracellular and intracellular signaling pathways are fixed. However, increased awareness of off-target effects coupled with a more contemporary knowledge of the adaptive nature of drug-disease networks within the dynamic chromatin interactome requires a re-examination of the focus on the single protein target-single functional perturbation paradigm in CNS drug discovery.

Drugs that act as agonists, partial antagonists, antagonists, or other neurotransmitter receptor modulators in the human CNS functionally alter molecules in receptor-mediated pathways downstream of the presumptive druggable target. For example, ketamine is a partial antagonist of the $N$-methyl-D-aspartate receptor and has been approved by the U.S. Food and Drug Administration for treatment-resistant depression (Daly et al., 2018), but related rapid antidepressant effects are exhibited by drugs that act downstream in this pathway, offering the potential as novel therapeutics in refractory depression (Gerhard et al., 2016). By analogy, it is possible to induce a transcriptional gene network whose output is therapeutic for a given clinical indication by targeting the druggable master regulators of the transcriptional network. Such targets may include large protein complexes involved in chromatin remodeling (Crabtree et al., 2018); transiently expressed transcription factors once thought to be undruggable (Crunkhorn, 2018; Sievers et al., 2018); functional regulatory RNAs, such as long noncoding RNA (lncRNA), microRNA, piRNA, and mRNA (Rizvi and Smith, 2017); or through alteration of a network gene or enhancer using direct genome editing delivered through gene therapy or viral vectors (Sheridan, 2017).

\section{B. The Functional Topology of the Three-Dimensional Spatial Genome}

Spatial contacts between enhancers of gene expression, gene promoters, and other elements in 3D genome space and the alteration of their interaction dynamics following drug treatment, during development, disease, and aging can now directly be examined using a new generation of methods that elucidate direct chromatin contacts in 3D and four dimensions (4D), a domain that may be called the "connectome" or "interactome" (Fraser and Bickmore, 2007). The ability to examine directly these interactions within the functional topology of the spatial genome has obviated the need to use network-based classification schemes that relied in the past on characteristics, such as inference of the functional relationships between protein products, the structural conversation of related protein products, or static pathway paradigms (Huang et al., 2009; Jiao et al., 2012; Wadi et al., 2016).

Complementary methods for the mapping and visualization of spatial and temporal interactions in chromatin between sequences and molecules that regulate gene transcription and their target genes have transformed biomedical research (Dekker et al., 2017). In 2012, the Encyclopedia of DNA Elements (ENCODE) program, funded by the U.S. National Institutes of Health (NIH), demonstrated that regulation of gene transcription acts through noncoding genomic regulation (The ENCODE Project Consortium, 2012). Researchers involved in the International Human Epigenome Consortia (Bujold et al., 2016; Stunnenberg et al., 2016; Stricker et al., 2017) and its component programs (Kundaje et al., 2015; Albrecht et al., 2016; Fernandez et al., 2016) have made tremendous strides in cataloging the hierarchy of transcription. Recently, within the context of the $4 \mathrm{D}$ Nucleome program sponsored by the U.S. NIH, studies of the three-dimensional (3D) genome provide a detailed understanding of how transcriptional control operates, as well as insight into the dynamics of structure-function relationships genomewide (Chen et al., 2015). This also includes previously under-appreciated properties of biologic networks (Rajapakse and Smale, 2017; Liu et al., 2018).

These trends impact our understanding of humandrug response mechanisms beyond so-called "epigenetic drugs" that modulate readers, writers, and erasers (Arrowsmith et al., 2012), leading to a unifying model of how xenobiotics and endogenous hormones modulate the functional topology of the human genome (Le Dily et al., 2014) in which entire transcriptional gene networks may be manipulated as a therapeutic intervention in disease (Crabtree et al., 2018; Crunkhorn, 2018; Sievers et al., 2018). The rapid pace of scientific discovery in regulatory genomics, coupled with a transformative understanding of the transcriptional hierarchy and spatial dynamics of the cell nucleus, provides us with the ability to resolve previously unrecognized and ill-defined mechanisms of action of psychotropic drugs that have been in clinical use for decades. Computational analysis of spatial, temporal, and mechanical systems in the pharmacoepigenome has revealed new CNS pharmacodynamic and pharmacokinetic networks (Higgins, et al., 2017a).

Evidence from multiple research studies show that many CNS drugs act on the same gene regulatory networks that contain disease risk variants (Hebbring et al., 2015; Higgins et al., 2015a, 2017a; Hu et al., 2016). In contrast to the orthodox notion of allele equivalency genomewide, we now recognize that, in most cases, causal SNPs that have been significantly associated to human traits in GWAS are located 
within euchromatin and display allele skewing (Kircher et al., 2014; Lee et al., 2015). Mutations that break the boundaries of TADs or disperse the repressive subset of TADs, called lamina-associated domains, have profound consequences for variation in drug response and the incidence of adverse drug events. Disruption of the rhythmic regulation of gene expression has profound consequences for response to medications and the incidence of adverse events in humans (Zhang et al., 2014). Conversely, unorthodox pharmacodynamic pathways, such as induction of neurogenesis in adult brain, are key mechanisms by which inhibitors of histone deacetylases exert their action in the CNS (Hsieh et al., 2004; Georgoff et al., 2016; Farzanehfar et al., 2017; Higgins et al., 2017a; Stephens et al., 2017, 2018). In addition, unconventional interpretation of drug response and remission SNPs from GWAS have markedly improved our understanding of how mutations alter molecular physiology of the cell leading to human pharmacogenomic variation (Higgins et al., 2015b).

Figure 1 illustrates our contemporary understanding of the noncoding regulatory genome, the characteristics of causal single nucleotide polymorphisms (SNPs) that are significantly associated with human drug response and adverse drug events from genomewide association studies (GWAS) and an overview of histone modifications that are discussed in this review. Figure 1A shows a pie chart analysis of all pharmacogenomic GWAS data as of January 15,2019 . This shows that the vast majority (81\%) of significant pharmacogenomic SNPs are located within either intragenic (intronic) or intergenic enhancers, with only $4 \%$ predicted to be missense coding variants. Figure $1 \mathrm{~B}$ shows an overview of chromatin compartments (A, B), the nucleosome, histone modifications, and the allele-specific nature of causal SNPs from GWAS. Causal SNPs are found in nucleosome-free domains and exhibit allele specificity as determined by methods such as DNase I hypersensitivity analysis, ATAC-seq, MNase-seq, and related techniques. Thus, using computational methods such as machine learning and deep learning, it has been possible to predict accurately whether a SNP is causal or not in a given cell type or tissue based on training sets that consist of known causal SNPs in these tissues in humans that exhibit allele specificity (Lee et al., 2015; Kelley et al., 2016; Li et al., 2016; Quang and Xie, 2016)). This strategy has redefined the domain of functional genomics.

Figure 1C illustrates the nucleosome core particle showing histones $\mathrm{H} 3, \mathrm{H} 4$, and $\mathrm{H} 2 \mathrm{~A}$, as well as the linker histone $\mathrm{H}$ and modifications of the lysine residues on the histone 3 tails. In studies of chromatin state annotation of regulatory elements (Bernstein et al., 2010; Kundaje et al., 2015), the combination of the marks histone 3 lysine 27 acetylation (H3K27ac) and histone 3 lysine 4 monomethylation (H3K4me1) have been used as surrogates for active enhancers, and the combination of the marks H3K27ac and histone 3 lysine 4 trimethylation (H3K4me3) have been used as surrogates for active promoters. As shown in Fig. 1C, histone modifications include H3K9, with H3K9ac indicative of domains of active gene expression (euchromatin), whereas H3K9me is indicative of domains of silenced gene expression (heterochromatin) (Allshire and Madhani 2018).

1. Spatial Topology and Gene Regulation within the Chromatin Environment. The spatial architecture and dynamics of the human genome determine which genes and RNAs are expressed and when they are expressed in a cell type-specific manner, both during development and aging, and following cellular perturbation by intrinsic and extrinsic stimuli. Supplemental Fig. 1 shows the spatial hierarchy of transcriptional organization as first determined by chromatin conformation capture methods. Chromosomes fill in much of the available volume of the nucleoplasm as chromosome territories (CTs) and contain circumscribed A and B compartments that consist of euchromatin and heterochromatin respectively (Lieberman-Aiden et al., 2009; $\mathrm{Yu}$ and Ren, 2017). Active genes tend to be located on the periphery of CTs, and inter-chromosomal looping between CTs provides the basis for a subset of enhancerpromoter and promoter-promoter spatial interactions in trans (Supplemental Fig. 1). The A and B chromatin compartments of CTs contain TADs within an average but highly variable length in linear sequence of approximately $1 \mathrm{Mb}$.

TADs were first characterized using chromatin conformation capture methods such as Hi-C, where initial scaling was consistent with a fractal globule model (Lieberman-Aiden et al., 2009; Dixon et al., 2012). Highresolution study of enhancer-promoter loops within TADs now include the organization of TAD boundary proteins including CCCTC-binding protein (CTCF), the cohesin complex (e.g., RAD21), and other proteins (Rao et al., 2014). Super-resolution light microscopic imaging (Cremer and Cremer, 2010) has also provided direct evidence of TADs and related architectural features (Rao et al., 2014; Wang et al., 2016). Supplemental text provides additional detail about the different topological and dynamic structures within the $4 \mathrm{D}$ nucleome and their roles in the regulation of gene transcription, including chromosome territories, A and B chromatin compartments, insulated neighborhoods, transcriptional hubs, TADs, lamina-associated domains, super-enhancers and stretch enhancers, frequently interacting regulatory elements, high-occupancy transcriptional domains, and nuclear pore complexes. In the following section, we describe the functional topology of the biologic structures of most relevance for this review-TADs and enhancerpromoter pairs.

a. Topologically associated domains. Within the cell's nucleus, recent studies detailing the hierarchy of transcriptional components have reinforced the 


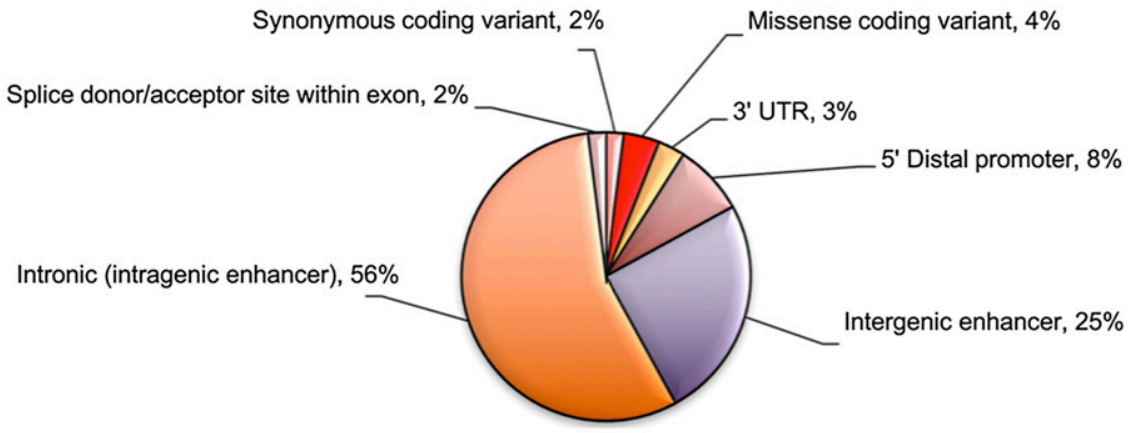

B

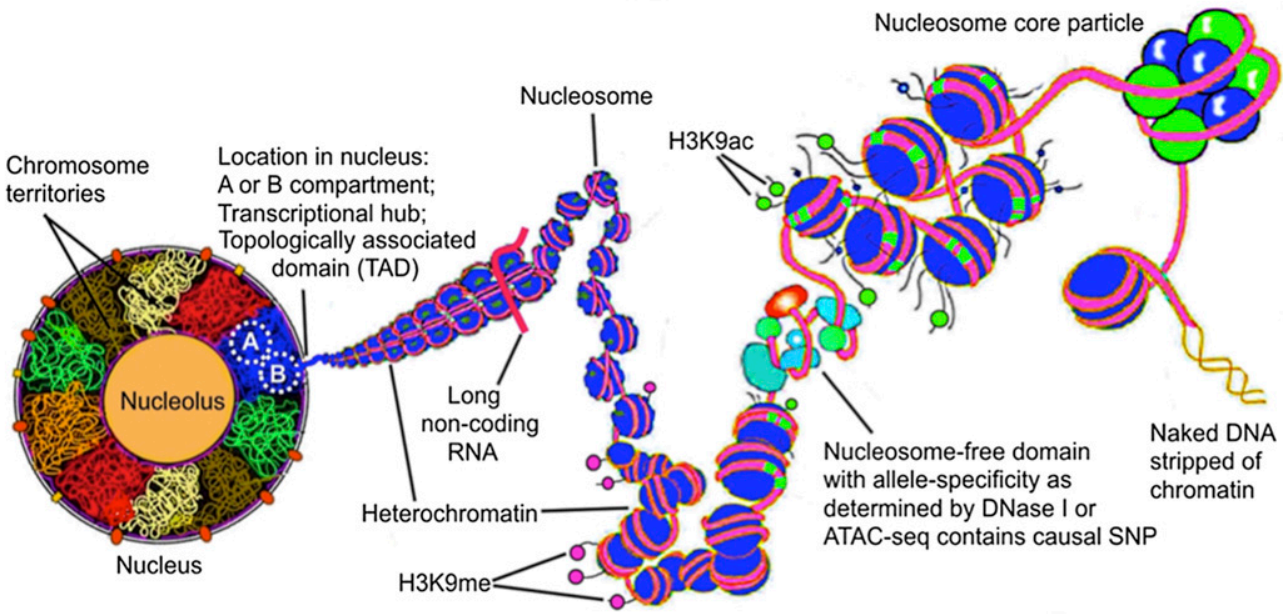

C

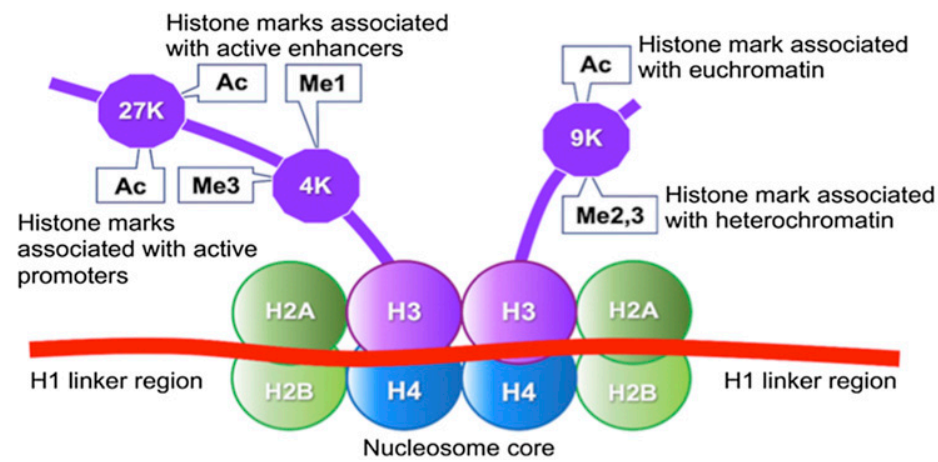

Fig. 1. The noncoding regulatory genome, causal SNPs and chromatin state. (A) Pharmacogenomic SNPs associated with drug response or adverse drug events from GWAS are predominately located within enhancers (81\%), and only $4 \%$ are called as exonic missense variants that could putatively disrupt protein structure or protein-protein interactions. (B) Illustration of genomic DNA, which is packaged within chromatin, and the different attributes of causal SNPs from GWAS that act on the epigenome. (C) Histone modifications significantly associated with enhancers, promoters, euchromatin, and heterochromatin the human genome.

adage that "structure encodes function." The fundamental spatial domain of transcription is the TAD located within CTs, spanning approximately $1 \mathrm{Mb}$ in linear sequence (ranging from $0.2 \mathrm{Mb}$ to over $4 \mathrm{MB}$ in length) and containing a variable number of genes, pseudogenes, long noncoding RNAs (lncRNAs) and DNA-dependent RNA polymerase (POLR2A). TADs are conserved as 3D structures among cell types and tissues (Lieberman-Aiden et al., 2009; Dixon et al., 2012, 2015), exhibiting some cell type-specific variation (Ghavi-Helm et al., 2019), and represent modules of transcriptional regulation (Dixon et al., 2015; Dai et al., 2016). For example, in humans,
$60 \%-70 \%$ of TAD structures are conserved between embryonic stem cells (ESCs) and adult differentiated cells (Dixon et al., 2015; Ji et al., 2016). In general, TADs exhibit specific histone modifications (Dixon et al., 2015; Ji et al., 2016) and are units of DNA replication timing (Pope et al., 2014). Specific TADs also comprise hormone-responsive coregulation modules (Le Dily et al., 2014). Intra-TAD functional interactions consisting of enhancer-promoter and promoter-promoter pairs are more frequent than are inter-TAD interactions (Cremer and Cremer, 2010; Dixon et al., 2015), and regulation in cis by enhancers constrained to promoters within a TAD 
appears common (Bonev and Cavalli, 2016; GonzalezSandoval and Gasser, 2016).

Transcriptionally active TADs are usually found in the interior of the nucleus and at the surface of chromosome territories (Wang et al., 2016). These TADs are highly enriched in interchromosomal contacts with a variety of different active promoters and enhancers on other chromosomes in trans (Fortin and Hansen, 2015; Dai et al., 2016; Tjong et al., 2016). These transinteracting TADs maintain strong intradomain structure and show higher than expected frequencies of contacting individual TADs on neighboring chromosomes, suggesting that TADs interact frequently with other chromosomes in trans as structurally-intact units.

TADs may be located at variable distances from one another, usually far in linear DNA sequence, and may cluster into compartments A or B. TADs segregated into one compartment or another tend to interact only with members of that compartment. Although some recent Hi-C data suggest sub-compartments in A and B, TADs can also switch compartments depending on cell types, treatment condition, and during cell fate commitment. Early Hi-C studies demonstrated that CTs are composed of cell type-specific A and B compartments, which consist of euchromatin and heterochromatin, respectively (Lieberman-Aiden et al., 2009; Dixon et al., 2012). $\mathrm{A}$ and $\mathrm{B}$ chromatin compartments can be approximated using eigenvector analysis of the genome contact matrix in Hi-C data using observation-expectation methods (Fortin and Hansen, 2015). These large A and B compartments have been demonstrated from a study using long-range correlations of epigenomic combination of DNA methylation microarray data, DNase I hypersensitivity, single-cell ATAC sequencing, and single-cell whole-genome bisulfite sequencing (Fortin and Hansen, 2015). Light microscopic analysis has confirmed the presence of these larger mesoscale euchromatin and heterochromatin structural domains across different cell types (Wang et al., 2016), as well as detailed mapping in human tissues and cell lines using Hi-C (Dai et al., 2016; Yu and Ren, 2017). In the human genome, there are approximately 2400 TADs (Dixon et al., 2012).

The results of quantitative analysis of TADs and TAD boundary strength in the human neuronal H1 cell line are shown in Fig. 2A. Most TADs (98\%) contain one or more validated or predicted noncoding enhancers. Only $8 \%$ of enhancers in these cell lines span adjacent TADs through TAD boundaries, while $13 \%$ of TADs in this cell line contain clusters of gene homologs. Few proteincoding genes are not bounded by TADs (7\%), and 30\% of known protein-coding genes span TAD boundaries; $47 \%$ of TADs in these cells are significant expression quantitative trait loci (eQTLs).

Figure 2A shows a data-driven analysis of TAD boundary strength genomewide in the human $\mathrm{H} 1$ neuronal cell type based on the density of the bound protein CTCF and significance of the TAD boundary with super-enhancers. The strength of TAD boundaries can be classified into five distinct domains based on the amount of CTCF bound to the boundary and whether a super-enhancer is colocated (Gong et al., 2017). The boundaries of TADs are relatively invariant between different human cell types and about $60 \%$ of the position of TAD boundaries are the same in the human and the mouse and are conserved among metazoans (Harmston et al., 2017). Short terminal repeats located within specific, densely methylated TAD boundaries as determined by Hi-C mapping of chromatin are associated with, or may be causal, for up to 25 neurologic diseases, including Huntington's disease, amyotrophic lateral sclerosis, Friedreich's ataxia, and cerebellar ataxia (Sun et al., 2017). Deletion of a TAD boundary containing the EPHA4 gene causes brachydactyly in humans (Lupiáñez et al., 2015).

Figure 2B demonstrates the critical nature of TAD boundaries in drug response. Of the 236 known superenhancers identified in human embryonic stem cells, genes encoding transcription factors and genes encoding known absorption, distribution, metabolism, and excretion proteins are most significantly associated with super-enhancers in humans. These gene classes are significantly different from random gene association with super-enhancers genomewide at a $P$ value of $5.78 \mathrm{E}-19$ for transcription factors and $2.37 \mathrm{E}-13$ for absorption, distribution, metabolism, and excretion genes (Fisher's exact test).

As the structure of TADs is relatively conserved across various cell types and species, it is highly likely that they play a key role in preserving the topology of chromosome folding (Andersson et al., 2014; Sexton and Cavalli, 2015; Ou et al., 2017). Evidence suggests that genes that occupy the same TAD are coregulated by enhancers and other regulatory elements. Dixon et al. (2015), however, emphasized that they are not analogous to the bacterial operon in which all genes are also regulated in a coordinated manner. Studies of eQTL in humans demonstrate that an eQTL significantly impacts subsets of genes that are constrained to the same TAD (Van Bortle et al., 2014; Grubert et al., 2015; Waszak et al., 2015). Experimental studies in mice show that a weak promoter-linked reporter inserted genomewide responds to adjacent enhancers and genes only when all the genes are contained within the same TAD (Liu et al., 2017). A comprehensive search of the FANTOM5 database revealed that every gene promoter targeted in cis by each annotated enhancer, when such information was available (Forrest et al., 2014), was always localized to the same TAD.

b. Enhancer-promoter pairs. Enhancers and promoters provide sub-TAD loop control of gene regulation, although other sub-TAD organizational units and features have been characterized. The control of 
A

\begin{tabular}{|c|c|c|}
\hline TADs that contain known or predicted enhancers & & $8 \%$ \\
\hline Enhancers that span adjacent TADs in cis & $8 \%$ & $92 \%$ \\
\hline TADs that contain clusters of gene homologues & $13 \%$ & $87 \%$ \\
\hline Protein coding genes located outside of TADs & $7 \%$ & $93 \%$ \\
\hline Protein coding genes that span 2 TADs & $30 \%$ & $70 \%$ \\
\hline TADs that are significant eQTLs $(p<1 \mathrm{E}-20)$ & $47 \%$ & $53 \%$ \\
\hline Class V TAD boundaries & $20 \%$ & $80 \%$ \\
\hline Class IV TAD boundaries & $11 \%$ & $89 \%$ \\
\hline Class III TAD boundaries & $27 \%$ & $73 \%$ \\
\hline Class II TAD boundaries & $11 \%$ & $89 \%$ \\
\hline Class I TAD boundaries & $31 \%$ & $69 \%$ \\
\hline TADs that are LADs & $20 \%$ & $80 \%$ \\
\hline
\end{tabular}

B

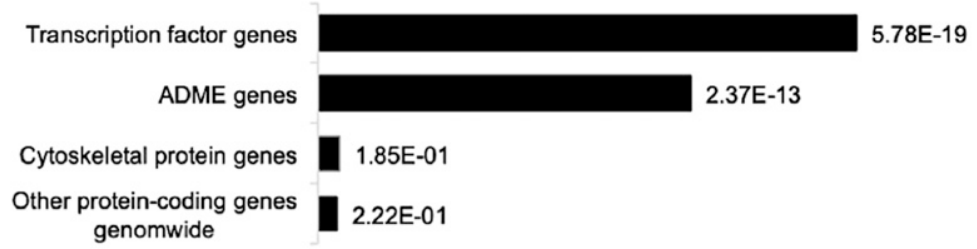

Fig. 2. Characteristics and distribution of human TADs. (A) Data-driven analysis of TADs, enhancers, protein-coding genes, and TADs boundaries in the $\mathrm{H} 1$ neuronal human cell line. (B) Human gene classes most significantly associated with super-enhancers in embryonic stem cells.

enhancer's spatial contacts to promoters is mediated by molecules such as CTCF and YY1 (Weintraub et al., 2017). Enhancers and promoters are virtually identical regulatory elements that serve as platforms for high occupancy by transcription factors (Bickmore 2013; Vernimmen and Bickmore, 2015; Yu and Ren, 2017). They exhibit very similar dynamic properties as cis-regulatory elements in the control of gene expression and both regulate genes transcribed by POLR2A. Although spatial interconnections between some promoters and enhancers may remain relatively fixed in a poised state during development, close examination of enhancer-promoter loops demonstrate that they associate and dissociate with rapid kinetics in adult mammals (Zhang et al., 2013).

Although there are different types of gene promoters (Li et al., 2012), the most common contain core components such as the transcription start site and proximal regulatory elements with more distal regulation driven by the activity of enhancers, which can activate or silence expression from the target promoter. During transcription, promoters bind general transcription factors, such as the multi-subunit complex consisting of TATA box-binding protein, and a set of TATA boxbinding protein-associated factors. Transcription then proceeds through a series of steps until functional elongation of RNA is reached.

Enhancers are enriched in core promoter elements but are $\mathrm{CpG}$ poor, whereas promoters are usually $\mathrm{CpG}$ rich and thus may be differentially impacted by DNA methylation in tissues other than the brain (Luo and
Ecker, 2015). Enhancers contain numerous binding sites for transcription factors in nucleosome-depleted regions that interact with coactivators, including the histone acetyltransferases p300/CREB-binding protein. Enhancers are brought into proximity with target promoters through chromatin looping (Rao et al., 2014) or through 3D tracking (Vernimmen and Bickmore, 2015), facilitated by the mediator complex, cohesion, and other proteins. Causal SNPs are found in nucleosome-depleted regions (NDRs), flanked by regions marked with specific histone modifications such as H3K4me1 and H3K27ac, which designate enhancers, and H3K27ac and marked by H3K4me3, which designate promoters (Fig. 1). Enhancer function is independent of orientation and distance to target promoters within a TAD and can be located $5^{\prime}, 3^{\prime}$ to the promoter, or most commonly, within introns-the latter designated as "intragenic enhancers" that rarely regulate the expression of the gene in which they are embedded (Bickmore, 2013; Dekker et al., 2017). Enhancer-promoter interactions are not a consequence of the proximity in linear DNA sequence, since most enhancers control promoters located beyond neighboring genes (Dixon et al., 2015; Vernimmen and Bickmore, 2015).

Insight into functional differences between enhancers and promoters has been provided by studies of transcriptional burst kinetics in animal models and human cell lines. Gene transcription appears to be stochastic (Levine and Tjian, 2003), and experimental data suggest that enhancers increase the probability of gene 
transcription (Walters et al., 1995). Artificially engineered enhancer-promoter chromatin loops have validated the role that enhancers play in the regulation of gene expression (Bartman et al., 2016). More recently, Larsson et al. (2019) demonstrated using allelic cell type-specific sequencing that gene expression is primarily determined through alterations in transcriptional burst frequencies. For so-called housekeeping genes, they found that the length of their genomic loci was negatively correlated with burst size but not burst frequency. Most importantly, transcriptome-wide analysis has demonstrated that enhancers are associated with transcriptional burst frequency and gene promoters are correlated with burst magnitude. This observation suggests that enhancers are the primary determinants of cell type-specific gene expression (Larsson et al., 2019).

c. Drug-disease networks. A major outcome of research in the network modeling of drug mechanisms is that they share many components with disease networks that serve as targets. This may appear obvious, as many compounds are designed to interfere with pathogenic systems to block disease progression. However, this intimate relationship extends not only to molecules within a specific pathway, but even to individual SNPs that are significantly associated with a disease phenotype that are shared with SNPs associated with response stratification by a drug that is used to treat the disorder (Higgins et al., 2015b, 2017a; Hu et al., 2016).

Phenome-wide association studies (PheWAS) use gene variants in a biorepository linked to clinical data from large sample sizes to examine systematically their impact across a broad range of human phenotypes (Denny et al., 2010; Bush et al., 2016). For example, missense and regulatory SNPs in the complement factor $\mathrm{H}$ gene, including rs1061170, and the SNP rs7529589 that impacts an enhancer in the disease tissue of origin, are significant risk variants associated with age-related macular degeneration in multiple GWAS of European American populations. These same variants are significantly associated with the degree of response to Visudyne (verteporfin for injection) (Bausch \& Lomb, Rochester, NY), a medication used to treat the disorder (Hebbring et al., 2015). Other shared PheWAS noncoding "super SNPs" include rs1333049, which is a significant disease risk SNP for coronary artery disease, stroke, type 2 diabetes, and atrial fibrillation, as well as stratification of drug response by $\beta$-blockers. The SNP rs9388451 has also been associated with electrocardiographic features such as QRS duration, QRS prolongation by the second-generation antipsychotic drug quetiapine, and lithium unmasking of Brugada syndrome (Bush et al., 2016).

Tissue-specific, regulatory cis- and trans-interacting community-based networks have been characterized by combining disease SNPs from GWAS with eQTL data
(Fagny et al., 2016). To detect regulatory communities, cis- and trans-eQTLs from 13 human tissues were mapped using bipartite graphs, in which significant eQTLs were revealed as edges of a bipartite network linking SNPs and gene nodes. SNPs that comprised significant associations were mapped as transcriptional hubs and genes were mapped as edges. This study demonstrated that eQTL communities are comprised of functionally related sets of variants, including GWAS SNPs, in a tissue-specific manner. In addition, for diseases such as chronic obstructive pulmonary disease, SNPs significantly associated with chronic obstructive pulmonary disease risk were enriched within eQTL intermediate nodes (Fagny et al., 2016). This is consistent with results suggesting that the genetic component of many disease phenotypes are combinations of GWAS SNPs of small to intermediate effect sizes, in contrast to causal pharmacogenomic SNPs identified from GWAS that exhibit moderate to large effects sizes (Higgins et al., 2015a).

There are numerous methods for modeling gene networks. These range from mapping of the physical spatial contacts between genes within the chromatin interactome (Dekker et al., 2017) for determination of drug spatial networks (G. A. Higgins et al., submitted manuscript) to the weighting of gene-gene interactions based on "relatedness" measures. This includes the class of proteins encoded by genes, predefined functional modules, and evolutionary relatedness (Huang et al., 2009; Jiao et al., 2012; Luna, et al., 2016; The Gene Ontology Consortium, 2019). With the emergence of chromosome conformation capture methods such as Hi-C combined with increases in knowledge of functional genomics, it is possible to physically map gene interactions in the context of spatial chromatin organization, without the need to rely on ad hoc architectures, ontologies, and/or classification schemes (Wadi et al., 2016; Dunn et al., 2017).

The adaptive plasticity of drug-gene regulatory networks is evident in phenotypes such as drug resistance, addiction, and habituation, which are phenomena that emerge over time. Although these are considered negative consequences of medication use and may be attributable to changes in drug target receptor physiology, closer examination suggests that this is an emergent property of drug-disease networks. Drug networks are characterized by the simultaneous presence of different subnetworks organized within separate layers, with links and nodes of qualitatively different types and quantitatively different features (Fagny et al., 2016; Hu et al., 2016). The concept of hardwired networks is inherently inaccurate, as adaptive rewiring of biologic networks is part of healthy physiology, disease progression and drug use, drug-drug interactions, and drug-gene interactions. Many of these studies have overemphasized candidate genes and molecules. Complexity, robustness, pleiotropy, and 
adaptation are as much attributes of drug regulatory networks as they are of any phenotype that contains a strong genetic component (Hu et al., 2016). Furthermore, few longitudinal studies examining the periodicities of pharmacogenomic gene expression in animal models or in humans have been conducted to date.

Furthermore, hormones such as progesterone, estrogen, and xenobiotics including psychotropic drugs, differentially expand and contract only a subset of the approximately $2400 \mathrm{TADs}$ in humans with concomitant changes in the expression of genes in the corresponding subset of TADs (Fig. 3, A and B) (Le Dily et al., 2014). For endogenous hormones, the numbers of differentially regulated TADs may be large, resulting in extensive regions that mediate steroid receptor-dependent remodeling of the genome (Le Dily et al., 2019), including networks of linked enhancers regulated by lncRNAs (Li et al., 2016).

In most cases, and especially within TADs that exhibit the strongest boundaries, enhancers are constrained to looping to gene and lncRNA targets contained within the same TAD. It is important to note that $3 \mathrm{D}$ genome architecture involving intra-TAD enhancer-promoter loops constrain linkage in human genetics and prove to be more accurate than traditional measures of linkage disequilibrium (Gerber et al., 2018; Whalen and Pollard, 2019). This was recently found to be the case in studies of postmortem human brain, as well as other tissues (Fig. 3C) (Giusti-Rodríguez et al., 2018). These results suggest that druggable transcriptional networks in the human genome are composed of functional architectural domains, including the spatial organization of the chromatin interactome.

\section{Neurogenic Transcriptional Mechanisms.} During the transition of blast cells to neurons, the developmental progression to terminally differentiated postmitotic cells, and reprogramming of astrocytes and neural progenitors in the adult brain, spatial contacts in chromatin (the "interactome") occur prior to gene expression (Cholewa-Waclaw et al., 2016; Krijger et al., 2016; Bonev et al., 2017; Higgins et al., 2017a; Liu et al., 2018). Neuroblasts exit the cell cycle initially as neuroepithelial cells, which subsequently become multipotent radial glia cells that reside in the subventricular germinal zone in the human CNS. Later in development, neurons turn on transcriptional programs of differentiation responsible for synaptogenesis, neuritogenesis, and axonal outgrowth.

An inherent feature of the journey from pluripotent stem cell to neuronal progenitor to terminally differentiated neuron is the ability to massively transform the chromatin interactome from one developmental stage to another as each new cellular phenotype is acquired. During development, histone acetylation and euchromatin chromatin are accompanied by expression of $\mathrm{npBAF}$ (neural progenitor $\mathrm{Brg} / \mathrm{Brm}$-associated factor, also known as SWI/SWF) following exit from the cell cycle of the developing multipotent neuroblast. Subsequently, most terminally differentiated postmitotic neurons in the human brain are held at $\mathrm{G}_{0}$ of the cell cycle, but other cells, including astrocytes and neural progenitor cells of the adult brain have the capacity to be reprogrammed into neurons (Niu et al., 2013; Su et al., 2014). Postmitotic terminally differentiated neurons in the human brain are associated with nBAF and shut down circumscribed pathways to reprogramming such as the human silencing complex HUSH, which acts to silence certain genes through hypermethylation of H3K9 (Allshire and Madhani, 2018).

Neurogenesis, neuronal development, and differentiation require coordinated timing of neuron cell type-specific patterns of chromatin remodeling and activation and/or repression of transcription factor gene networks that modulate enhancer-promoter looping mechanisms (de la Torre-Ubieta et al., 2018; Gallegos et al., 2018; Rajarajan et al., 2018; Yoon et al., 2018). Although it is possible to discriminate different transcriptional signatures of neurogenesis from those of neuronal differentiation by examining radial glial progenitor cells of the germinal zone from differentiated neurons of the cortical plate in humans, the latter of which contain human brain-specific genes responsible for cortical expansion (Mashtalir et al., 2018), it is not possible to accurately discretize different stages of neuronal development. The temporal stages of stemness, proliferation, neurogenesis, cell division, and differentiation are not precisely linear, but rather proceed in bursts of cell fate commitment and terminal differentiation. Different cell type-specific transcriptional networks of neurogenesis overlap with those of differentiation, because pluripotent neuronal stem-like blast cells acquire neuronal cell fate and switch from cell proliferation to neurogenic cell division in cerebral cortex (Sokpor et al., 2018).

The capacity of the adult and aging human brain for neurogenesis has been a controversial topic in neuroscience research, although evidence of neurogenesis has emerged from decades of research (van Praag et al., 2002; Boldrini et al., 2018; Snyder, 2019). Psychotropic drugs such as valproic acid can induce neurogenesis from human astrocytes in culture and within injured tissue (Kwon et al., 2012; Su et al., 2014; Yin et al., 2019). Antidepressant medications and behavioral therapies, including active concentrative meditation, can enhance gray matter preservation and potentiate neurogenesis during healthy aging and in neuropsychiatric disease (Santarelli et al., 2003; Eisch and Petrik, 2012; Luders et al., 2013; Mehrmann and Karmacharya, 2013). Unambiguous demonstration of neurogenesis does not preclude the beneficial effects associated with activation of neurogenic transcriptional networks for the preservation of neuronal integrity. As with many 
No drug:

Topologically-associated domains (TADs) are geometrically condensed

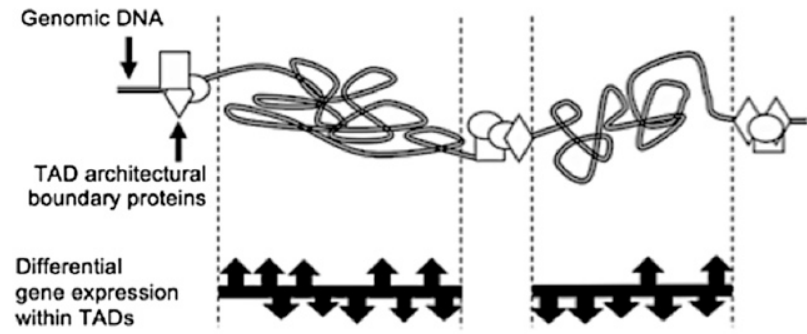

B Psychotropic drug:

Specific TADs are geometrically expanded, and specific intra-TAD gene expression is activated or suppressed by enhancer(s)-gene promoters contacts

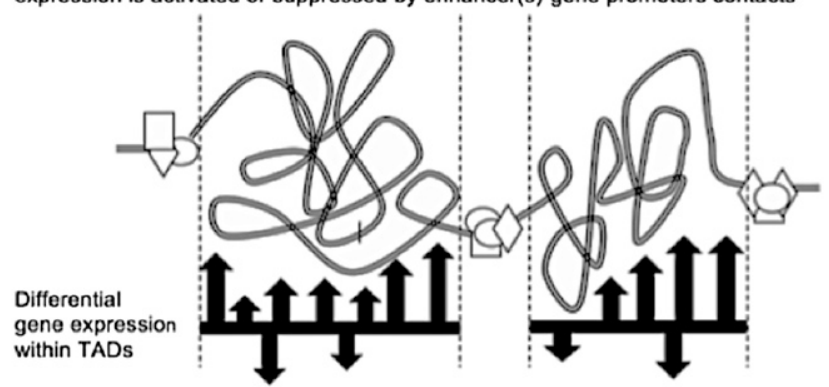

C TAD structure in the human genome provides more accurate linkage of the gene targets of enhancer SNPs from GWAS than do loci that are in high linkage disequilibrium

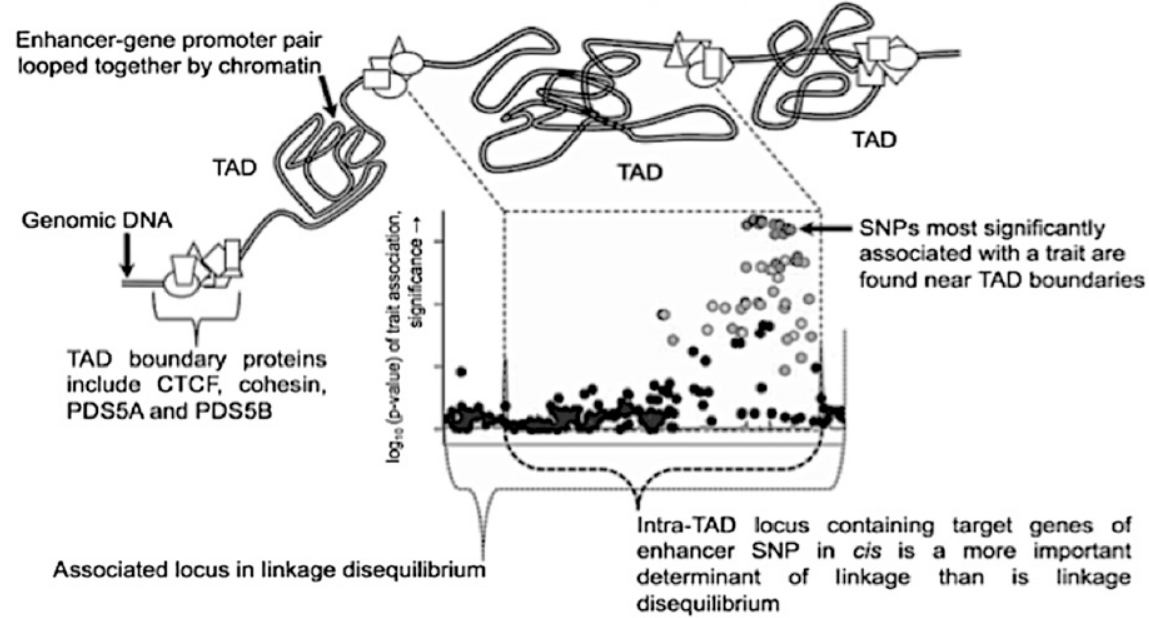

Fig. 3. Drugs act to differentially activate and suppress circumscribed sets of TADs concomitant with differential gene expression through alteration of the geometry of the $3 \mathrm{D}$ genome. (A and B) Schematic depiction of two adjacent TADs, which are expanded driving differential gene expression following drug exposure. (C) Causal SNPs from GWAS are most found within noncoding enhancers, and their target gene promoter set is more likely to be within the same TAD.

processes in molecular physiology, initiation of developmental programming in lieu of metastasis may provide therapeutic efficacy in many disorders. For example, in an animal model of heart failure, experimental restoration of the circadian regulation of myogenic responsiveness significantly improved cardiac function (Kroetsch et al., 2018). Similarly, the cytokine cardiotrophin 1 drives developmental myogenic transcription recapitulating the key features of cardiac cell development including transient and reversible hypertrophy of the myocardium and increased vascularity (Abdul-Ghani et al., 2017). The inhibitory pregnane steroid allopregnanolone induces neurogenic transcription without overt neurogenesis, reversing cognitive deficits in a mouse model of degenerative disease (Wang et al., 2010).

\section{Results}

\section{A. Characterization of Enhancer-Promoter}

Topologically Associated Domain Loops from the PsychENCODE Consortium

Recent articles from researchers in the National Institute of Mental Health-funded PsychENCODE Consortium have examined neurogenic transcriptional networks and enhancer-promoter TAD loops in neurons during development and in neuropsychiatric disease. These included experiments using postmortem fetal 
and adult human brain tissue, induced pluripotent neuronal stem cells, neuro-organoids, human cells transformed into neurons using retinoic acid (ATRA, a morphogen), biopsied human olfactory tissue, and neuronal cell lines (de la Torre-Ubieta et al., 2018; Girdhar et al., 2018; Li et al., 2018; Mashtalir et al., 2018; Rajarajan et al., 2018; Rhie et al., 2018; Wang et al., 2018; Yoon et al., 2018). Research results include the characterization of specific enhancer-promoter chromatin loops within TADs that characterize neural progenitor cells and neurogenic transcriptional networks in the adult human neocortex (de la TorreUbieta et al., 2018), the dynamics of transcriptional regulatory networks during morphogen-induced neurogenesis and neuronal differentiation (), the significant association between disordered neurogenic transcription networks and psychiatric disease ( $\mathrm{Li}$ et al., 2018), and the impact of disease on transcriptional networks shared among different psychiatric disorders (Gandal et al., 2018).

Using schizophrenia and its risk loci derived from GWAS data as an example, research from the PsychENCODE Consortium provides insight into the noncoding enhancer-promoter loops and associated genes within circumscribed TADs impacted genomewide, a common regulatory lncRNA (DGCR5) for a subset of risk loci, a specific altered transcription factor (POU3F2) neurogenic transcriptional network, and histone alterations in the frontal lobe in schizophrenia (Chen et al., 2018; Girdhar et al., 2018; Meng et al., 2018; Rajarajan et al., 2018). These studies provide insight into the genomic architecture underlying this range of psychiatric disorders that have eluded researchers for decades.

1. Control of Neurogenic Transcriptional Networks by Chromatin Remodeling Complexes. One particular class of proteins that control transcriptional gene networks during neuronal development are the BAF chromatin remodeling complexes including neural progenitor $\mathrm{BAF}$, which is associated with early neurogenesis, and neuronal BAF, which is associated with terminal differentiation (Bachmann et al., 2016; Hodges et al., 2018; Mashtalir et al., 2018). The switch from npBAF to nBAF includes swapping of SS18 (and SS18like proteins) with SOX10 (CREST), as well as replacement of DPF2 (BAF45D) with DPF1 (BAF45B) and DPF3 (BAF45C), ACTL6A (BAF53A) with ACTL6B (BAF53B), and addition of SMARCD3 (BAF60C). Several of the $\mathrm{nBAF}$ members such as SOX10 are responsible for processes associated with neuronal differentiation, such as dendrite outgrowth. The npBAF and $\mathrm{nBAF}$ chromatin remodeling complexes are not fixed, and their composition may vary with different neuronal cell types or physiologic states.

The BAF complexes are one of several types of known chromatin remodeling complexes that include the histone deacetylase multiprotein complex responsible for maintaining stem cell pluripotency, the INO80/SWR1 helicase complexes that recruit the transcription factor YY1 to gene promoters, the ATP-dependent chromatin assembly factor, or imitation switch family, which reposition nucleosomes and the HUSH/SETDB1 complex, in part responsible for heterochromatin formation in terminally differentiated neurons (Lyst et al., 2006). Although our knowledge is still incomplete, some of the chromatin remodeling complexes require ATP to function and some do not, and certain transcription factors and other proteins may be part of one or more complexes.

Results from several groups demonstrate that the BAF chromatin remodeling complexes, like other chromatin remodeling complexes, target active promoters and enhancers (Hnisz et al., 2013; Pulice and Kadoch, 2016). For example, loss of the SMARCB1 (BAF 47) or ARID1A (BAF 250A) subunits disrupts enhancer activation (Mathur et al., 2017), but loss of SMARCB1 (BAF 47) does not appear to impair gene promoter activation when polycomb repression may be present to maintain the chromatin environment at the promoter (Pulice and Kadoch, 2016). These data suggest differences between chromatin plasticity and maintenance at enhancerpromoter pairs in development and disease.

The neuronal BAF remodeling complexes control large transcriptional networks during the transition of neuroblasts to neurons, and are also involved in the reprogramming and plasticity of CNS cells. This shift in the neurogenic epigenome includes competition between different subunits during BAF complex recomposition that accompanies the transition from the npBAF complex to the nBAF complex (Lessard et al., 2007; Wu et al., 2007; Bachmann et al., 2016). A remarkable feature of the BAF remodeling complex is that while they are protein complexes which contain actin, the composite proteins function as transcription factors while embedded in the macromolecule.

SNPs, microdeletions, duplications, and other mutations of the genes and their regulatory elements that encode the BAF chromatin remodeling complex proteins profoundly impact neurodevelopmental processes (Fig. 4). These mutations in human neurologic disease and psychiatric disorders, as well as several human cancers, represent druggable candidates found within drug-disease networks (Ronan et al., 2013; Kadoch and Crabtree, 2015; Kadoch et al., 2017; Sokpor et al., 2018). Figure 4 shows examples of npBAF and nBAF genes that are mutated in schizophrenia, autism spectrum disorder, Coffin-Siris and related neurodevelopmental disorders, cognitive impairment, and dementia in Lewy body disease. Although some of the disorders are rare, their physiologic impact can be severe. Results from bioinformatics analysis of these gene sets show that they are significantly enriched for biologic processes including nucleosome and chromatin remodeling (Supplemental Table 3.1); molecular functions including 

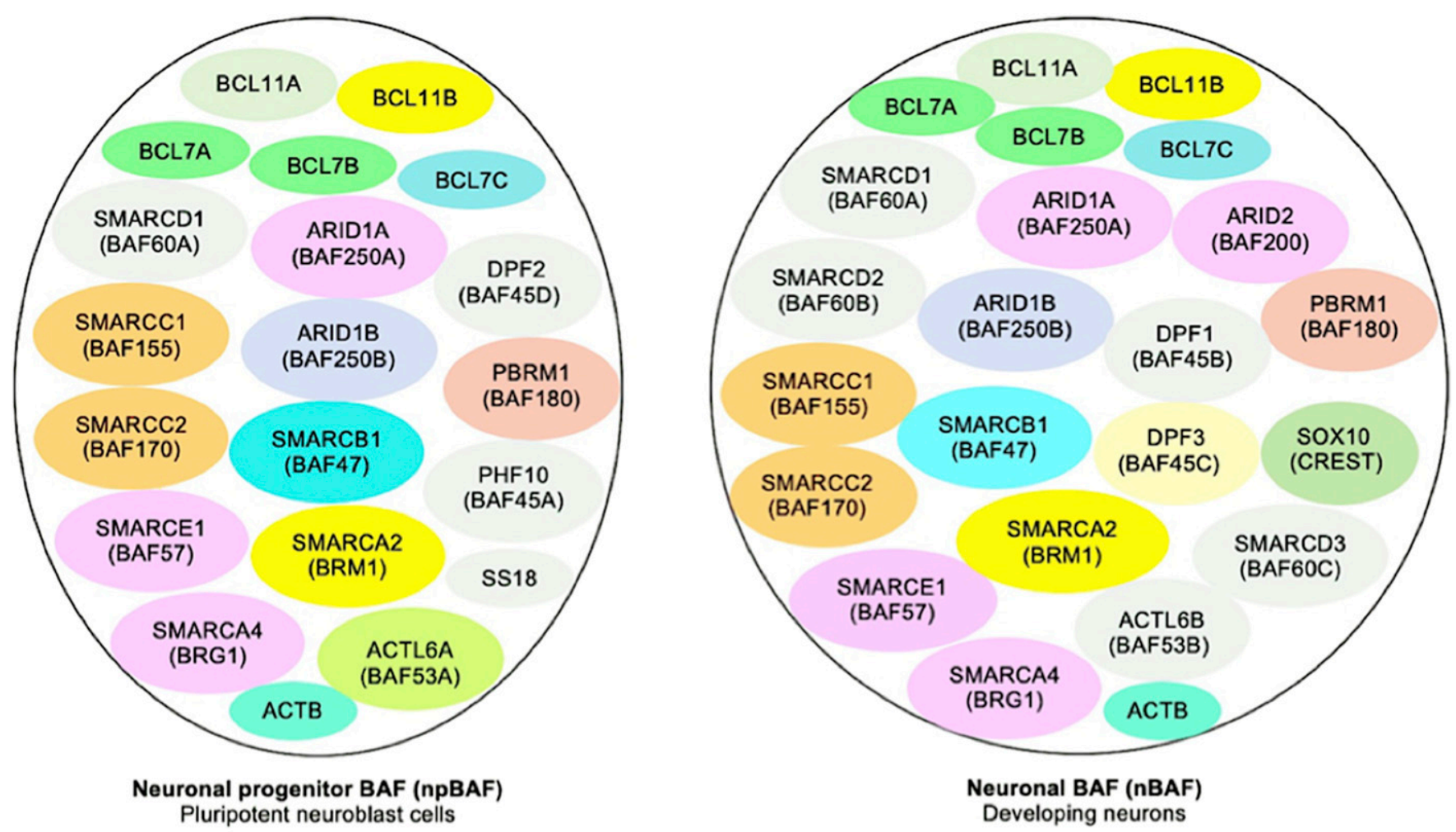

\begin{tabular}{|l|l|}
\hline & Schizophrenia \\
\hline & Autism spectrum disorder \\
\hline & Coffin-Siris syndrome \\
\hline & Coffin-Siris syndrome and Kleefstra's syndrome \\
\hline & Schizophrenia, autism spectrum disorder, intellectual disability, Coffin-Siris syndrome, microcephaly \\
\hline Sensory and intellectual impairment \\
\hline Cognitive impairment \\
\hline Dementia with Lewy body disorder \\
\hline 7q11.23 Duplication syndrome, including diverse neurological, psychiatric and other disorders \\
\hline & Hirschsprung's disease (enteric nervous system) \\
\hline & Peripheral demyelinating neuropathy, central dysmyelination, Waardenburg syndrome \\
\hline & Baraistser-Winter syndrome, Dystonia juvenile-onset \\
\hline
\end{tabular}

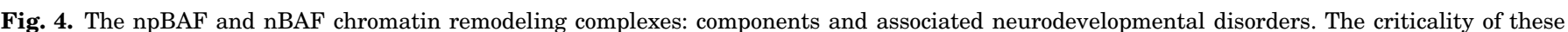

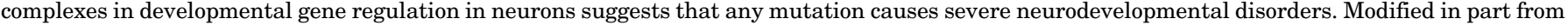
Ronan et al. (2013) and Sokpor et al. (2018). For gene names, please see Supplemental Table 1.

transcription coactivator activity, nucleosome binding, and chromatin binding (Supplemental Table 3.2); and diseases including Coffrin-Siris syndrome and Nicolaides-Baraitser syndrome (Supplemental Table 3.3), with the most significant xenobiotic upstream regulator identified as $(S)$-duloxetine (Supplemental Table 3.4) (Krämer et al., 2013, The Gene Ontology Consortium, 2019)

Another layer of complexity involves master transcription factors that control the various BAF component genes, which are shown as blue in the spatial network diagram in Fig. 5A. These various properties of BAF subunits, designated individually by different numbers related to their molecular weight, has led to some confusion in the research community. For example, the genes that encode ACTL6A, ARID1A, BCL11B, PBRM1, SMARCA4, SMARCE1, and SOX10 have been identified in multiple studies of human neurogenic transcriptional networks, including those from the PsychENCODE Consortium, with no apparent recognition of their function as components of the $\mathrm{npBAF}$ and $\mathrm{nBAF}$ chromatin remodelers and the transcription factors that regulate these complexes (de la TorreUbieta et al., 2018; Rajarajan et al., 2018) (Fig. 5A).

2. Network Analysis of Druggable Chromatin Remodeling and Neurogenic Mechanisms. In the context of larger neurogenic transcriptional networks, our pharmacoinformatics approach has been used to clarify the results from multiple studies to parse which control elements within these networks constituted probable druggable control elements. To achieve this objective, we combined contemporary bioinformatics methods of network analysis, based on a range of spatial organization and dynamics studies of genome organization with data from pharmacogenomic regulation in human populations, the chromatin interactome, and 


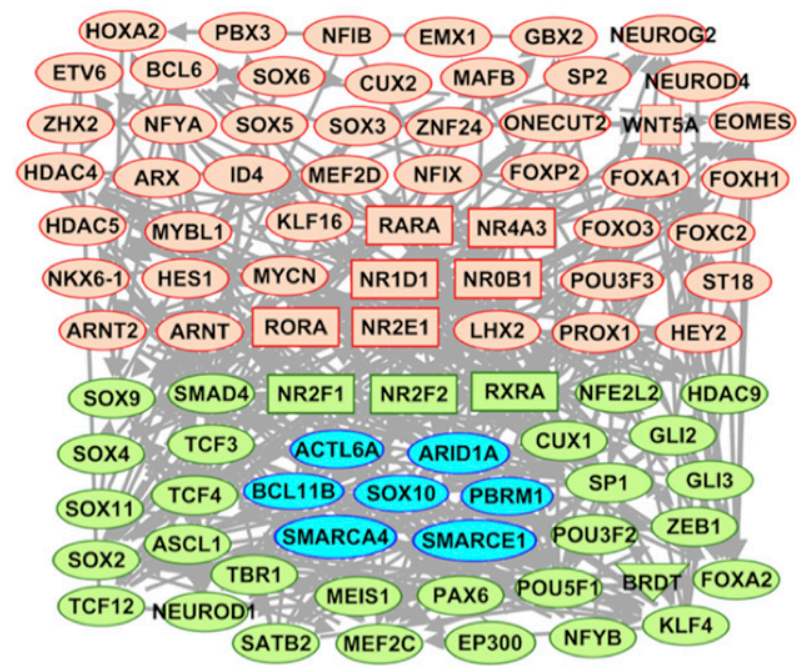

\begin{tabular}{|l|l|}
\hline & Transcription factors (oval) and nuclear receptors (rectangular) reported in PsychENCODE studies \\
\hline & Master transcription factor and nuclear receptors that control npBAF and nBAF reported in PsychENCODE studies \\
\hline & Transcription factor genes that encode subunits of npBAF and nBAF reported in PsychENCODE studies \\
\hline
\end{tabular}

B

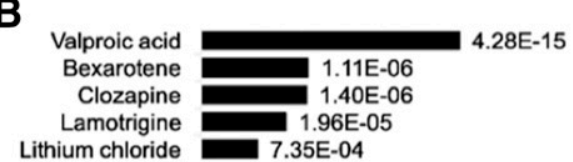

C

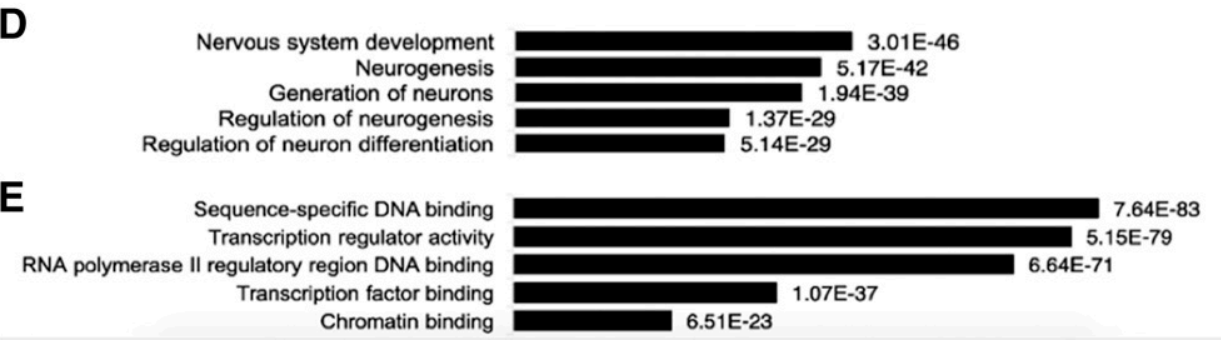

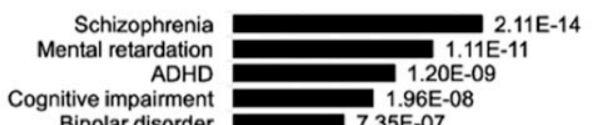

nitive impairment Bipolar disorder

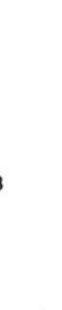

Fig. 5. Transcription factor and nuclear receptor genes identified in enhancer-promoter TAD loops within neurogenic transcriptional networks in studies from the PsychENCODE Consortium and related research. (A) Output from IPA (Krämer et al., 2013) of a highly interconnected pathway involved in neurologic development and disorders $(P=1 \times 10 \mathrm{E}-130)$. (B) Top upstream chemical-drug regulators of the network shown in (A) as determined by IPA and KEGG (Kanehisa et al., 2016). (C) Top five human neurologic disorders significantly associated with neurogenic network. (D) Top five human nervous system biologic processes. (E) Top five molecular functions determined by Gene Ontology (The Gene Ontology Consortium, 2019). For gene names, please see Supplemental Table 2.

putative pharmacodynamic targets obtained from drugbased network analysis. Thus, for this review, we undertook to reinterpret some of these results using a different approach, combining contemporary knowledge of the 4D Nucleome, enhancer and gene promoter analysis, measures of TAD localization and boundary strength, and chromatin biology with analysis of master pharmacogenomic regulatory networks (see Supplemental Methods and Results, Supplemental Fig. 5 in Supplemental Data for details).

In the analysis from the PsychENCODE Consortium and related studies, researchers used a variety of open resource methods and resources, including weighted gene co-expression network analysis (Langfelder and Horvath, 2008), Gene Ontology enrichment (The Gene Ontology Consortium, 2019), resources from the Pathway Commons database (Luna et al., 2016), and DAVID (Database for Annotation, Visualization and Integrated
Discovery) (Huang et al., 2009; Jiao et al., 2012). Although this research has yielded a wealth of new data, it has not been focused on the identification of druggable gene regulatory networks (Imoto et al., 2006). In addition, some of the bioinformatics software in these studies use infrequently updated gene- and proteincentric data that have proven to be inaccurate when used for high-throughput gene set enrichment and pathway analysis (Wadi et al., 2016; Dunn et al., 2017) and does not reflect the current understanding of the 4D Nucleome (Konopka et al., 2012; Chen et al., 2015; Dekker et al., 2017; Higgins et al., 2017b).

Our re-examination demonstrate that results from the PsychENCODE Consortium exhibit considerable enrichment of common pharmacogenomic elements within transcriptional networks significantly associated with neurogenesis and neuronal differentiation, including shared components of the npBAF and nBAF 
remodeling complexes and the master transcription factors that associate with the gene networks encoding these complexes. Available data on drug-gene set regulation found in commercial and open source drug databases were analyzed using KEGG and Ingenuity Pathway Analysis (Krämer et al., 2013; Kanehisa et al., 2016; Zhu et al., 2018) to determine the most significant associations of neurogenic transcriptional networks with currently prescribed psychotropic medications. The results showed significant association of neurogenic transcriptional networks with valproic acid. This analysis was followed by assessment of the union of gene sets from several studies followed by gene set enrichment using Gene Ontology for biologic process and molecular function (The Gene Ontology Consortium, 2019).

Figure 5A shows a consensus spatial network of 89 transcription factors, nuclear receptors, and chromatin remodelers based on data provided by the PsychENCODE Consortium, which were reanalyzed using our pharmacoinformatics platform (Higgins et al., 2017a; Allyn-Feuer et al., 2018) and displayed as a pathway by IPA (Krämer et al., 2013). Results from bioinformatics analysis of the larger 275 gene set from which this consensus spatial network was derived are shown in Supplemental Table 4.1 (biologic processes, Gene Ontology), Supplemental Table 4.2 (molecular functions, Gene Ontology), Supplemental Table 4.3 (diseases and functions), and Supplemental Table 4.4 (most significant xenobiotic controllers).

In the consensus spatial network, only direct genegene interactions that reached threshold criterion were used in this analysis (see Supplemental Methods and Results and Supplemental Fig. 5 for details). The genes form a statistically significant interconnected spatial network based on all available data sources, with a $P$ value of $1 \mathrm{E}-130$ (Fisher's exact test). In Fig. 5A, the genes are labeled according to the proteins that they encode, including transcription factors (orange), master transcription factors that were determined post hoc to regulate $\mathrm{npBAF}$ and/or $\mathrm{nBAF}$ chromatin remodeling complexes from our analysis (green), or as genes that encode components of the npBAF and/or nBAF complexes. The latter category includes ACTL6A, ARID1A, BCL11B, PBRM1, SMARCA4, SMARCE1, and SOX10 and are labeled as blue in Fig. 5A.

Figure 5B shows the upstream xenobiotic regulators of this spatial network as determined by IPA pathway analysis (Krämer et al., 2013) and KEGG (Kanehisa et al., 2016). The top five most significant psychotropic drugs that control this network are valproic acid $(P=4.28 \mathrm{E}-15)$, bexarotene $(P=1.11 \mathrm{E}-06)$, clozapine (1.20E-06), lamotrigine (1.96E-05), and lithium chloride (7.35E-04). Using disease risk variant analysis, which includes results from GWAS and PheWAS, it was found the top five neuropsychiatric diseases that are significantly associated with mutations in this neurogenic transcriptional gene network are schizophrenia $(P=2.11 \mathrm{E}-14)$, mental retardation $(P=1.11 \mathrm{E}-11)$, attention deficit hyperactivity disorder $(P=1.20 \mathrm{E}-09)$, cognitive impairment $(P=1.96 \mathrm{E}-07)$, and bipolar spectrum disorder $(P=7.35-07)$, as shown in Fig. 5C.

Figure 5, C and D, shows the results of enrichment of the entire neurogenic transcriptional network for biologic process and molecular function as determined by Gene Ontology (The Gene Ontology Consortium, 2019) filtered for human nervous tissue. Biologic process analysis using Gene Ontology demonstrated that this consensus neurogenic transcriptional network was enriched for nervous system development $(P=3.01 \mathrm{E}-46)$, neurogenesis $(P=5.17 \mathrm{E}-42)$, generation of neurons $(P=1.94 \mathrm{E}-39)$, regulation of neurogenesis $(P=1.37 \mathrm{E}-29)$, and regulation of neuron differentiation $(P=5.14-29)$. Enriched molecular function included sequence-specific DNA binding $(P=7.64 \mathrm{E}-83)$, transcription regulator activity $(P=5.15 \mathrm{E}-79)$, RNA polymerase II regulatory regions binding $(P=6.64 \mathrm{E}-71)$, transcription factor binding $(P=1.07-37)$, and chromatin binding $(P=6.51 \mathrm{E}-23)$. This analysis suggested that, despite the widespread effects of HDAC inhibitors in human brain such as valproic acid, with part of its mechanism impacting neurogenic transcription, we should explore this as a widespread action of other novel psychotropic drugs as well.

Together, these analyses suggested that valproic acid and other psychotropic drugs could act in a specific manner on the proteins encoded by neurogenic transcriptional networks. For example, bexarotene, an antineoplastic agent approved by the FDA for treatment of cutaneous $\mathrm{T}$ cell lymphoma, with offlabel use in non-small cell lung cancer and breast cancer, is a significant upstream controller of both small and large neurogenic transcriptional networks (see Supplemental Methods and Results and Supplemental Fig. 5 for details). The drug is a retinoid that selectively activates retinoid $\mathrm{X}$ receptors, but exhibits little activity at retinoid A receptors. In clinical trials, bexarotene significantly reduced symptoms of schizophrenia when used as a novel adjuvant therapeutic agent (Lerner et al., 2013). Although further trials are not yet underway, two studies of neurogenic transcriptional pathways from the PsychENCODE Consortium provide support for continuing trials of this drug for treatment of schizophrenia (Giusti-Rodríguez et al., 2018; Rajarajan et al., 2018). Bexarotene is a compound that was developed originally for adjunctive therapy in schizophrenia based on alteration of neurodevelopment called "the retinoid dysregulation hypothesis" (Goodman, 1994).

As a further example, valproic acid exhibits efficacy for multiple conditions, including as an antiepileptic, mood stabilizer, and providing protection against migraine. This drug exhibits a promiscuous and broad impact as an HDAC (histone deacetylase) inhibitor. It may be that its effectiveness in these disorders are likely a consequence of valproic acid's potent ability to acetylate 
the H3K9 moiety, altering chromatin structure in a nonspecific manner, leading to a variety of unrelated downstream signaling effects. However, in a well-characterized large animal model of traumatic brain injury, and, in other animal models of CNS injury, administration of supratherapeutic doses of valproic acid following brain injury protects against gray matter loss compared with placebo infusion (Georgoff et al., 2016; Higgins et al., 2017a; Chang et al., 2019). These results show that valproic acid exerts a neuroprotective effect, probably acting through activation of neurogenic transcriptional networks within existing neurons without requiring significant neurogenesis. Although these results are promising, significant association of valproic acid with neurogenic transcription does not yet prove that this drug acts as a targeted controller of any specific neurogenic transcriptional network. More specific and related biologic mechanisms need to be investigated to better understand the biologic role of valproic acid and other psychotropic medications during neuronal development and to determine how it acts in a therapeutic manner on drug-disease networks.

\section{Discussion}

\section{A. Emerging Trends in the Druggability of Transcriptional Regulatory Networks}

There are proximal and distal therapeutic strategies for targeting proteins or nucleic acids in humans, which control transcriptional networks that are already being undertaken for intractable disorders in which a single target is thought to be limited to a discrete mechanism of action. In the future, druggable targets that regulate networks will likely include master transcription factors, chromatin remodeling complexes or their subunits, long noncoding RNAs (lncRNAs), enhancers, promoters, and other intrinsic molecular regulators.

Direct, formidable approaches are beginning to be used in humans, including genome-editing methods (e.g., CRISPR-Cas9, TALEN), which are beginning to enter human trials. One of the first examples to be used was modification of the enhancer of the BCL11A gene promoter to interrupt the BAF chromatin remodeling complex switch to adult $\beta$-globulin, resulting in the persistence of fetal hemoglobin in sickle cell disease and potentially other hemoglobinopathies (Zeng et al., 2018). The BCL11A enhancer not only acts as a switch for the BAF complex in blood cells, but also targets other genes within the same TAD (Canver et al., 2015).

A proximal nucleic acid target currently in clinical trials is the SMN1 locus, in which gene therapy using an artificial regulatory gene construct is delivered via an adenovirus-associated virus vector (AAV) (Zhou et al., 2018). This therapy is intended to ameliorate spinal muscle atrophy, a devastating neuromuscular disease that is the leading cause of death in infants, affecting 1 in 10,000 live births. The synthetic construct to be

A

Adeno-associated virus vector (AAV)

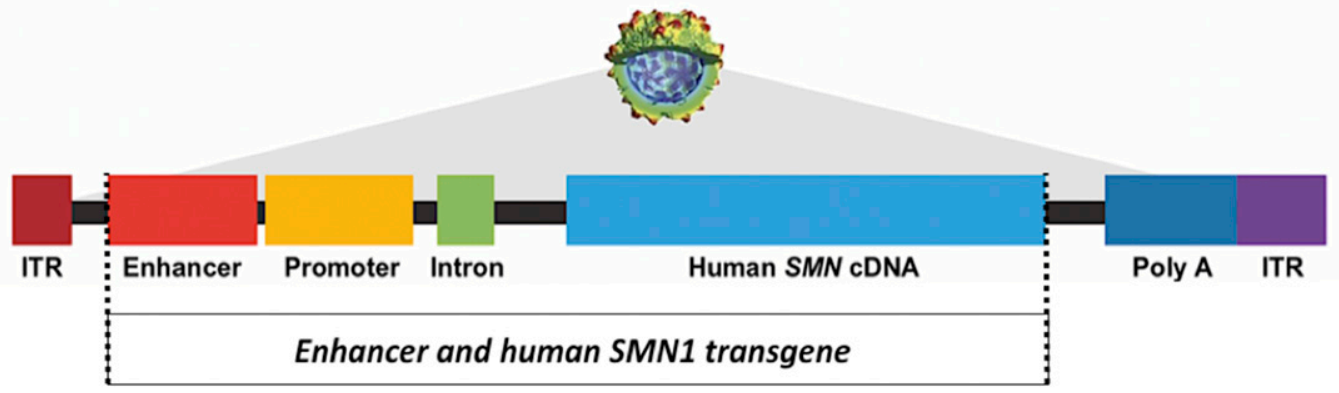

B

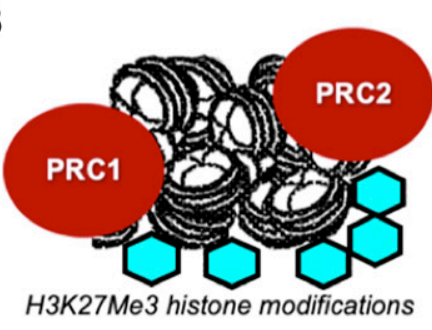

POUF51 locus repressed by H3K27Me3 under the control of PRC1 and PRC2 polycomb heterochromatin

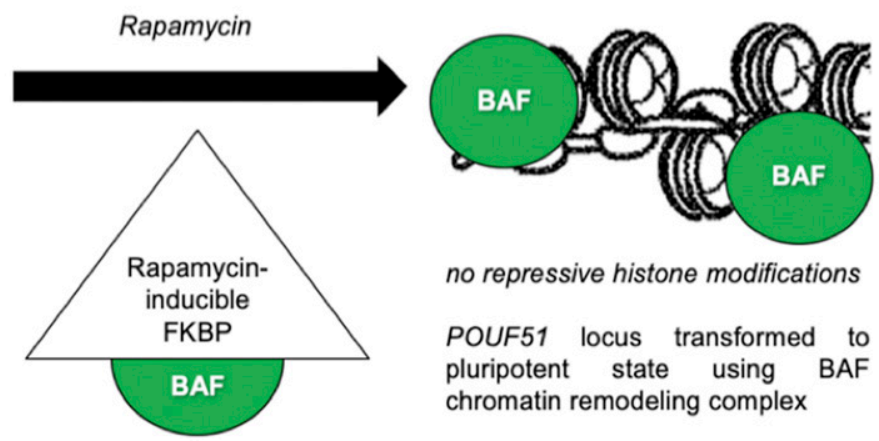

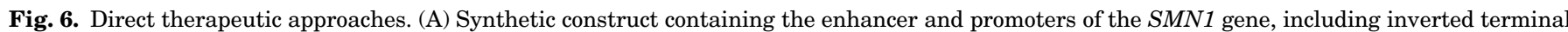

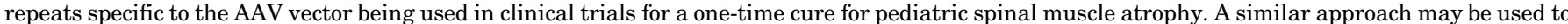

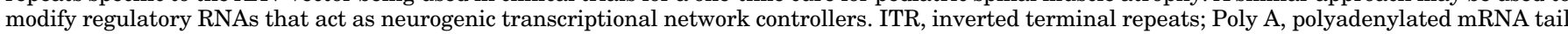

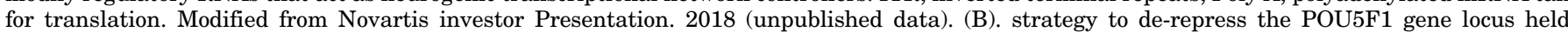

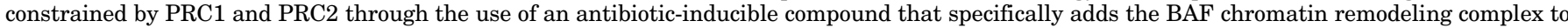
the gene, allowing it to re-assume control of a pluripotent control network modified from Crabtree et al. (2018) and Young, (2011). 
delivered by the AAV vector contains the enhancer and gene promoter of the $S M N 1$ gene, as well as an intron and cDNA of the human coding sequence along with self-complementary AAV terminal repeats, which presumably increase the rate of transcription to produce healthy SMN protein (Fig. 6A). A similar strategy may be used to target regulatory RNAs, such as the lncRNA $D G C R 5$, to establish appropriate control of a neurogenic transcriptional network in schizophrenia responsible for the regulation of a subset of risk gene targets in the disorder (Meng et al., 2018).

It is also possible to use a small, chimeric fusion protein to target a network controller with great accuracy. Crabtree et al. (2018) used this method to recruit the BAF remodeling complex to the POU5F1 locus to reestablish pluripotency in mouse embryonic fibroblasts by driving away polycomb heterochromatin repressed by H3K27Me3 (Young, 2011). In this instance, the chimeric therapy might be composed of a rapamycin-inducible, small molecular vehicle such as FKBP (under $1000 \mathrm{Da}$ ). One example of this approach is illustrated in Fig. 6B, where the BAF remodeler occupies the POUF51 gene locus displacing polycomb repression, releasing this master transcription factor from inhibition so that it may resume transcriptional network control.

More indirect, distal therapeutics may be employed to drive the accumulation of depletion of a master transcription factor through manipulation of the kinetics of its degradation. This strategy was employed by Sievers et al. (2018), in which the "degrome" specific to a type of transcription factor was modified to abolish its activity. Through understanding the zinc finger motif properties present in the $\mathrm{C} 2 \mathrm{H} 2$ family of transcription factors and through selection of analogs induced that specifically degraded circumscribed sets of $\mathrm{C} 2 \mathrm{H} 2$ zinc finger-containing factors, properties of a weakly druggable CRBN ubiquitin ligase with similar zinc fingers could be exploited. Through novel thalidomide analog drugs with chemical alterations at the Cys2-His2 $(\mathrm{C} 2 \mathrm{H} 2)$ zinc finger-drug-CRBN interface, thalidomide analogs could selectively induce degradation of distinct sets of $\mathrm{C} 2 \mathrm{H} 2$ transcription factors.

The discovery of novel gene network approaches to existing psychotropic medications, such as valproic acid and bexarotene, which appear to impact neurogenic transcriptional control networks lends credence to the hypothesis that induction of these networks, while they may or may not lead to neurogenesis in the adult human brain, may reanimate neurogenic transcription in adult neurons, resulting in extending the longevity of gray matter. While the nascent therapeutic mechanisms discussed here carry the additional burden of targeting specific neuronal cell populations in the human central nervous system, they offer promise for the alleviation of neurodevelopment and neurodegenerative disorders impacted by deficits in neurogenesis and neurogenic maturation.

\section{Acknowledgments}

The authors thank Dr. James S. Burns for a careful reading of the manuscript and many useful suggestions. They thank Ms. Janet Peake for manuscript support and for helping with the submission process.

\section{Authorship Contributions}

Participated in research design: Higgins, Athey.

Conducted experiments: Higgins.

Contributed new reagents or analytic tools: Higgins.

Performed data analysis: Higgins, Ade.

Wrote or contributed to the writing of the manuscript: Higgins, Williams, Ade, Alam, and Athey.

\section{References}

Abdul-Ghani M, Suen C, Jiang B, Deng Y, Weldrick JJ, Putinski C, Brunette S, Fernando P, Lee TT, Flynn P, et al. (2017) Cardiotrophin 1 stimulates beneficial myogenic and vascular remodeling of the heart. Cell Res 27:1195-1215.

Akbarian S, Liu C, Knowles JA, Vaccarino FM, Farnham PJ, Crawford GE, Jaffe AE Pinto D, Dracheva S, Geschwind DH, et al.; PsychENCODE Consortium (2015) The PsychENCODE project. Nat Neurosci 18:1707-1712.

Albrecht F, List M, Bock C, and Lengauer T (2016) DeepBlue epigenomic data server: programmatic data retrieval and analysis of epigenome region sets. Nucleic Acids Res 44 (W1):W581-W586.

Allis CD and Jenuwein T (2016) The molecular hallmarks of epigenetic control. Nat Rev Genet 17:487-500.

Allshire RC and Madhani HD (2018) Ten principles of heterochromatin formation and function. Nat Rev Mol Cell Biol 19:229-244.

Allyn-Feuer A, Ade A, Luzum JA, Higgins GA, and Athey BD (2018) The pharmacoepigenomics informatics pipeline defines a pathway of novel and known warfarin pharmacogenomics variants. Pharmacogenomics 19:413-434.

Andersson R, Gebhard C, Miguel-Escalada I, Hoof I, Bornholdt J, Boyd M, Chen Y, Zhao X, Schmidl C, Suzuki T, et al. (2014) An atlas of active enhancers across human cell types and tissues. Nature 507:455-461.

Arrowsmith CH, Bountra C, Fish PV, Lee K, and Schapira M (2012) Epigenetic protein families: a new frontier for drug discovery. Nat Rev Drug Discov 11: 384-400.

Bachmann C, Nguyen H, Rosenbusch J, Pham L, Rabe T, Patwa M, Sokpor G, Seong RH, Ashery-Padan R, Mansouri A, et al. (2016) mSWI/SNF (BAF) complexes are indispensable for the neurogenesis and development of embryonic olfactory epithelium. PLoS Genet 12:e1006274 Available from: 10.1371/journal.pgen.1006274.

Bartman CR, Hsu SC, Hsiung CC, Raj A, and Blobel GA (2016) Enhancer regulation of transcriptional bursting parameters revealed by forced chromatin looping. Mol Cell 62:237-247.

Bernstein BE, Stamatoyannopoulos JA, Costello JF, Ren B, Milosavljevic A, Meissner A, Kellis M, Marra MA, Beaudet AL, Ecker JR, et al. (2010) The NIH roadmap epigenomics mapping consortium. Nat Biotechnol 28:1045-1048.

Berson A, Sartoris A, Nativio R, Van Deerlin V, Toledo JB, Porta S, Liu S, Chung CY, Garcia BA, Lee VM, et al. (2017) TDP-43 promotes neurodegeneration by impairing chromatin remodeling. Curr Biol 27:3579-3590.e6.

Bickmore WA (2013) The spatial organization of the human genome. Annu Rev Genomics Hum Genet 14:67-84

Boldrini M, Fulmore CA, Tartt AN, Simeon LR, Pavlova I, Poposka V, Rosoklija GB, Stankov A, Arango V, Dwork AJ, et al. (2018) Human Hippocampal Neurogenesis Persists throughout Aging. Cell Stem Cell 22 (4):589-599.e5.

Bonev B and Cavalli G (2016) Organization and function of the 3D genome. Nat Rev Genet 17:661-678.

Bonev B, Mendelson Cohen N, Szabo Q, Fritsch L, Papadopoulos GL, Lubling Y, Xu X, Lv X, Hugnot JP, Tanay A, et al. (2017) Multiscale 3D genome rewiring during mouse neural development. Cell 171:557-572.e24.

Braun SMG, Kirkland JG, Chory EJ, Husmann D, Calarco JP, and Crabtree GR (2017) Rapid and reversible epigenome editing by endogenous chromatin regulators. Nat Commun 8:560.

Bujold D, Morais DAL, Gauthier C, Côté C, Caron M, Kwan T, Chen KC, Laperle J, Markovits AN, Pastinen T, et al. (2016) The international human epigenome consortium data portal. Cell Syst 3:496-499.e2.

Bush WS, Oetjens MT, and Crawford DC (2016) Unravelling the human genomephenome relationship using phenome-wide association studies. Nat Rev Genet 17: 129-145.

Canver MC, Smith EC, Sher F, Pinello L, Sanjana NE, Shalem O, Chen DD, Schupp PG, Vinjamur DS, Garcia SP, et al. (2015) BCL11A enhancer dissection by Cas9mediated in situ saturating mutagenesis. Nature 527:192-197.

Chang P, Williams AM, Bhatti UF, Biesterveld BE, Liu B, Nikolian VC, Dennahy IS, Lee J, Li Y, and Alam HB (2019) Valproic acid and neural apoptosis, inflammation, and degeneration 30 days after traumatic brain injury, hemorrhagic shock, and polytrauma in a swine model. J Am Coll Surg 228:265-275.

Chen H, Chen J, Muir LA, Ronquist S, Meixner W, Ljungman M, Ried T, Smale S, and Rajapakse I (2015) Functional organization of the human 4D Nucleome. Proc Natl Acad Sci USA 112:8002-8007.

Chen C, Meng Q, Xia Y, Ding C, Wang L, Dai R, Cheng L, Gunaratne P, Gibbs RA, Min S, et al. (2018) The transcription factor POU3F2 regulates a gene coexpression network in brain tissue from patients with psychiatric disorders. Sci Transl Med 10:eaat8178 Available from: 10.1126/scitranslmed.aat8178.

Cholewa-Waclaw J, Bird A, von Schimmelmann M, Schaefer A, Yu H, Song H, Madabhushi R, and Tsai LH (2016) The role of epigenetic mechanisms in the 
regulation of gene expression in the nervous system. $J$ Neurosci $\mathbf{3 6}$ 11427-11434.

Chu T, Zhou H, Lu L, Kong X, Wang T, Pan B, and Feng S (2015) Valproic acidmediated neuroprotection and neurogenesis after spinal cord injury: from mechanism to clinical potential. Regen Med 10:193-209.

Crabtree GR, Braun SM, Calarco JP, and Kadoch C (2018) inventors, Leland Stanford Junior University, assignee. Methods of inducibly targeting chromatin effectors and compositions for use in the same. U.S. Patent Application 15/769,331. 2018 Oct 25.

Cremer T and Cremer M (2010) Chromosome territories Available from: 10.1101/ cshperspect.a003889, Cold Spring Harb Persepect Biol 2, p a003889.

Crunkhorn S (2018) Drug discovery: targeting transcription factors. Nat Rev Drug Discov 18:18.

Dai C, Li W, Tjong H, Hao S, Zhou Y, Li Q, Chen L, Zhu B, Alber F, and Jasmine Zhou $\mathrm{X}$ (2016) Mining 3D genome structure populations identifies major factors governing the stability of regulatory communities. Nat Commun 7:11549.

Daly EJ, Singh JB, Fedgchin M, Cooper K, Lim P, Shelton RC, Thase ME, Winokur A, Van Nueten L, Manji H, et al. (2018) Efficacy and safety of intranasal esketamine adjunctive to oral antidepressant therapy in treatment-resistant depression: a randomized clinical trial. JAMA Psychiatry 75:139-148.

Dekker J, Belmont AS, Guttman M, Leshyk VO, Lis JT, Lomvardas S, Mirny LA, O'Shea CC, Park PJ, Ren B, et al.; 4D Nucleome Network (2017) The 4D nucleome project. Nature 549:219-226.

Dekker J and Mirny L (2016) The 3D genome as moderator of chromosomal communication. Cell 164:1110-1121.

de la Torre-Ubieta L, Stein JL, Won H, Opland CK, Liang D, Lu D, and Geschwind DH (2018) The dynamic landscape of open chromatin during human cortical neurogenesis. Cell 172:289-304.e18.

Denny JC, Ritchie MD, Basford MA, Pulley JM, Bastarache L, Brown-Gentry K, Wang D, Masys DR, Roden DM, and Crawford DC (2010) PheWAS: demonstrating the feasibility of a phenome-wide scan to discover gene-disease associations. Bioinformatics 26:1205-1210.

Dixon JR, Jung I, Selvaraj S, Shen Y, Antosiewicz-Bourget JE, Lee AY, Ye Z, Kim A, Rajagopal N, Xie W, et al. (2015) Chromatin architecture reorganization during stem cell differentiation. Nature 518:331-336.

Dixon JR, Selvaraj S, Yue F, Kim A, Li Y, Shen Y, Hu M, Liu JS, and Ren B (2012) Topological domains in mammalian genomes identified by analysis of chromatin interactions. Nature 485:376-380.

Dunn W Jr, Burgun A, Krebs MO, and Rance B (2017) Exploring and visualizing multidimensional data in translational research platforms. Brief Bioinform 18 $1044-1056$

ENCODE Project Consortium (2012) An integrated encyclopedia of DNA elements in the human genome. Nature 489:57-74.

Eisch AJ and Petrik D (2012) Depression and hippocampal neurogenesis: a road to remission? Science 338:72-75.

Fagny M, Paulson JN, Kuijjer M, Sonawane AR, Chen CY, Lopes-Ramos CM, Glass K, Quackenbush J, and Platig J (2016) A network-based approach to eQTL interpretation and SNP functionalcharacterization. bioRxiv Available from: 10.1101/ 086587.

Farzanehfar P, Horne MK, and Aumann TD (2017) Can valproic acid regulate neurogenesis from nestin + cells in the adult midbrain? Neurochem Res 42:2127-2134

Forrest AR, Kawaji H, Rehli M, Baillie JK, de Hoon MJ, Haberle V, Lassmann T, Kulakovskiy IV, Lizio M, Itoh M, et al.; FANTOM Consortium and the RIKEN PMI and CLST (DGT) (2014) A promoter-level mammalian expression atlas. Nature 507:462-470.

Fortin JP and Hansen KD (2015) Reconstructing A/B compartments as revealed by Hi-C using long-range correlations in epigenetic data. Genome Biol 16:180.

Fraser P and Bickmore W (2007) Nuclear organization of the genome and the potential for gene regulation. Nature 447:413-417.

Gallegos DA, Chan U, Chen LF, and West AE (2018) Chromatin regulation of neuronal maturation and plasticity. Trends Neurosci 41:311-324.

Gandal MJ, Zhang P, Hadjimichael E, Walker RL, Chen C, Liu S, Won H, van Bakel H, Varghese M, Wang Y, et al.; PsychENCODE Consortium (2018) Transcriptomewide isoform-level dysregulation in ASD, schizophrenia, and bipolar disorder. Science 362:eaat8127 Available from: 10.1126/science.aat8127.

Georgoff PE, Halaweish I, Nikolian VC, Higgins GA, Bonham T, Tafatia C, Remmer H, Menon R, Liu B, Li Y, et al. (2016) Alterations in the human proteome following administration of valproic acid. J Trauma Acute Care Surg 81:1020-1027.

Gerber S, Fournier D, Hewel C, and Horenko I (2018) Imputation of posterior linkage probability relations reveals a significant influence of structural $3 \mathrm{D}$ constraints on linkage disequilibrium. bioRxiv Available from: 10.1101/255315.

Gerhard DM, Wohleb ES, and Duman RS (2016) Emerging treatment mechanisms for depression: focus on glutamate and synaptic plasticity. Drug Discov Today 21 : $454-464$.

Ghavi-Helm Y, Jankowski A, Meiers S, Viales RR, Korbel JO, and Furlong EEM (2019) Highly rearranged chromosomes reveal uncoupling between genome topology and gene expression. Nat Genet 51 (8):1272-1282.

Girdhar K, Hoffman GE, Jiang Y, Brown L, Kundakovic M, Hauberg ME, Francoeur NJ, Wang YC, Shah H, Kavanagh DH, et al. (2018) Cell-specific histone modification maps in the human frontal lobe link schizophrenia risk to the neuronal epigenome. Nat Neurosci 21:1126-1136.

Giusti-Rodríguez P, Lu L, Yang Y, Crowley CA, Liu X, Bryois J, Crowley JJ, et al (2018) Schizophrenia and a high-resolution map of the three-dimensional chromatin interactome of adult and fetal cortex. bioRxiv 406330

Gong Y, Lazaris C, Sakellaropoulos T, Lozano A, Kambadur P, Ntziachristos P, Aifantis I, and Tsirigos A (2017) Stratification of TAD boundaries identified in reproducible Hi-C contact matrices reveals preferential insulation of superenhancers by strong boundaries. bioRxiv Available from: 10.1038/s41467-01803017-1.
Gonzalez-Sandoval A and Gasser SM (2016) On TADs and LADs: spatial control over gene expression. Trends Genet 32:485-495.

Goodman AB (1994) Retinoid dysregulation as a cause of schizophrenia. Am J Psychiatry 151:452-453.

Grubert F, Zaugg JB, Kasowski M, Ursu O, Spacek DV, Martin AR, Greenside P, Srivas R, Phanstiel DH, Pekowska A, et al (2015) Genetic control of chromatin states in humans involves local and distal chromosomal interactions. Cell $\mathbf{1 6 2}$ 1051-1065.

Guo W, Xu Y, and Feng X (2017) DeepMetabolism: a deep learning system to predict phenotype from genome sequencing. arXiv arXiv:1705.03094.

Harmston N, Ing-Simmons E, Tan G, Perry M, Merkenschlager M, and Lenhard B (2017) Topologically associating domains are ancient features that coincide with Metazoan clusters of extreme noncoding conservation. Nat Commun 8:441.

Hebbring SJ, Rastegar-Mojarad M, Ye Z, Mayer J, Jacobson C, and Lin S (2015) Application of clinical text data for phenome-wide association studies (PheWASs). Bioinformatics 31:1981-1987.

Higgins GA, Allyn-Feuer A, and Athey BD (2015a) Epigenomic mapping and effect sizes of noncoding variants associated with psychotropic drug response. Pharmacogenomics 16:1565-1583.

Higgins GA, Allyn-Feuer A, Barbour E, and Athey BD (2015b) A glutamatergic network mediates lithium response in bipolar disorder as defined by epigenome pathway analysis. Pharmacogenomics 16:1547-1563.

Higgins GA, Allyn-Feuer A, Georgoff P, Nikolian V, Alam HB, and Athey BD (2017a) Mining the topography and dynamics of the 4D Nucleome to identify novel CNS drug pathways. Methods 123:102-118.

Higgins GA, Georgoff P, Nikolian V, Allyn-Feuer A, Pauls B, Higgins R, Athey BD, and Alam HE (2017b) Network reconstruction reveals that valproic acid activates neurogenic transcriptional programs in adult brain following traumatic injury. Pharm Res 34:1658-1672.

Hnisz D, Abraham BJ, Lee TI, Lau A, Saint-André V, Sigova AA, Hoke HA and Young RA (2013) Transcriptional super-enhancers connected to cell identity and disease. Cell 155:934-947.

Hodges HC, Stanton BZ, Cermakova K, Chang CY, Miller EL, Kirkland JG, Ku WL, Veverka V, Zhao K, and Crabtree GR (2018) Dominant-negative SMARCA4 mutants alter the accessibility landscape of tissue-unrestricted enhancers. Nat Struct Mol Biol 25:61-72.

Hsieh J, Nakashima K, Kuwabara T, Mejia E, and Gage FH (2004) Histone deacetylase inhibition-mediated neuronal differentiation of multipotent adult neural progenitor cells. Proc Natl Acad Sci USA 101:16659-16664.

Hu JX, Thomas CE, and Brunak S (2016) Network biology concepts in complex disease comorbidities. Nat Rev Genet 17:615-629.

Huang W, Sherman BT, and Lempicki RA (2009) Systematic and integrative analysis of large gene lists using DAVID bioinformatics resources. Nat Protoc 4:44-57.

Imoto S, Tamada Y, Araki H, Yasuda K, Print CG, Charnock-Jones SD, Sanders D, Savoie CJ, Tashiro K, Kuhara S, et al. (2006) Computational strategy for discovering druggable gene networks from genome-wide RNA expression profiles. Pac Symp Biocomput 559-571.

Ji X, Dadon DB, Powell BE, Fan ZP, Borges-Rivera D, Shachar S, Weintraub AS, Hnisz D, Pegoraro G, Lee TI, et al. (2016) 3D chromosome regulatory landscape of human pluripotent cells. Cell Stem Cell 18:262-275.

Jiao X, Sherman BT, Huang da W, Stephens R, Baseler MW, Lane HC, and Lempick RA (2012) DAVID-WS: a stateful web service to facilitate gene/protein list analysis. Bioinformatics 28:1805-1806.

Kadoch C and Crabtree GR (2015) Mammalian SWI/SNF chromatin remodeling complexes and cancer: mechanistic insights gained from human genomics. Sci Adv 1:e1500447 Available from: 10.1126/sciadv.1500447.

Kadoch C, Williams RT, Calarco JP, Miller EL, Weber CM, Braun SM, Pulice JL, Chory EJ, and Crabtree GR (2017) Dynamics of BAF-Polycomb complex opposition on heterochromatin in normal and oncogenic states. Nat Genet 49:213-222.

Kanehisa M, Furumichi M, Tanabe M, Sato Y, and Morishima K (2016) KEGG: new perspectives on genomes, pathways, diseases and drugs. Nucleic Acids Res 45 (D1): D353-D361.

Kelley DR, Snoek J, and Rinn JL (2016) Basset: learning the regulatory code of the accessible genome with deep convolutional neural networks. Genome Res 26 990-999.

Kircher M, Witten DM, Jain P, O'Roak BJ, Cooper GM, and Shendure J (2014) A general framework for estimating the relative pathogenicity of human genetic variants. Nat Genet 46:310-315.

Konopka G, Friedrich T, Davis-Turak J, Winden K, Oldham MC, Gao F, Chen L, Wang GZ, Luo R, Preuss TM, et al. (2012) Human-specific transcriptional networks in the brain. Neuron 75:601-617.

Krämer A, Green J, Pollard J Jr, and Tugendreich S (2013) Causal analysis approaches in ingenuity pathway analysis. Bioinformatics 30:523-530.

Krijger PH, Di Stefano B, de Wit E, Limone F, van Oevelen C, de Laat W, and Graf T (2016) Cell-of-origin-specific 3D genome structure acquired during somatic cell reprogramming. Cell Stem Cell 18:597-610.

Kroetsch JT, Alibhai FJ, Lidington D, Reitz C, Zhang H, Heximer SP, Martino A and Bolz SS (2018) Disrupting a circadian clock mechanism that regulates myogenic reactivity mitigates cardiac injury in heart failure. Atherosclerosis $\mathbf{3 2}$ (Supp): 108-109.

Kundaje A, Meuleman W, Ernst J, Bilenky M, Yen A, Heravi-Moussavi A, Kheradpour P, Zhang Z, Wang J, Ziller MJ, et al.; Roadmap Epigenomics Consortium (2015) Integrative analysis of 111 reference human epigenomes. Nature 518: $317-330$.

Kwon JS, Kim GH, Kim DY, Lee BN, Lee B, Kim JH, Min BY, and Kim MS (2012) Neural differentiation of rat muscle-derived stem cells in the presence of valproic acid: a preliminary study. J Tissue Eng Regenerat Med 9:10-16.

Langfelder P and Horvath S (2008) WGCNA: an R package for weighted correlation network analysis. BMC Bioinformatics 9:559. 
Larsson AJM, Johnsson P, Hagemann-Jensen M, Hartmanis L, Faridani OR, Reinius B, Segerstolpe Å, Rivera CM, Ren B, and Sandberg R (2019) Genomic encoding of transcriptional burst kinetics. Nature 565:251-254.

Le Dily F, Baù D, Pohl A, Vicent GP, Serra F, Soronellas D, Castellano G, Wright RHG, Ballare C, Filion G, et al. (2014) Distinct structural transitions of chromatin topological domains correlate with coordinated hormone-induced gene regulation. Genes Dev 28:2151-2162.

Le Dily F, Vidal E, Cuartero Y, Quilez J, Nacht AS, Vicent GP, CarbonellCaballero J, Sharma P, Villanueva-Cañas JL, Ferrari R, et al. (2019) Hormone-control regions mediate steroid receptor-dependent genome organization. Genome Res 29:29-39.

Lee D, Gorkin DU, Baker M, Strober BJ, Asoni AL, McCallion AS, and Beer MA (2015) A method to predict the impact of regulatory variants from DNA sequence. Nat Genet 47:955-961.

Lerner V, Miodownik C, Gibel A, Sirota P, Bush I, Elliot H, Benatov R, and Ritsner MS (2013) The retinoid X receptor agonist bexarotene relieves positive symptoms of schizophrenia: a 6-week, randomized, double-blind, placebo-controlled multicenter trial. J Clin Psychiatry 74:1224-1232.

Lessard J, Wu JI, Ranish JA, Wan M, Winslow MM, Staahl BT, Wu H, Aebersold R, Graef IA, and Crabtree GR (2007) An essential switch in subunit composition of a chromatin remodeling complex during neural development. Neuron 55:201-215.

Levine M and Tjian R (2003) Transcription regulation and animal diversity. Nature 424:147-151.

Li G, Ruan X, Auerbach RK, Sandhu KS, Zheng M, Wang P, Poh HM, Goh Y, Lim J, Zhang J, et al. (2012) Extensive promoter-centered chromatin interactions provide a topological basis for transcription regulation. Cell 148:84-98.

Li M, Santpere G, Imamura Kawasawa Y, Evgrafov OV, Gulden FO, Pochareddy S, Sunkin SM, Li Z, Shin Y, Zhu Y, et al.; BrainSpan Consortium; PsychENCODE Consortium; PsychENCODE Developmental Subgroup (2018) Integrative functional genomic analysis of human brain development and neuropsychiatric risks. Science 362:eaat7615 Available from: 10.1126/science.aat7615.

Li S, Alvarez RV, Sharan R, Landsman D, and Ovcharenko I (2017) Quantifying deleterious effects of regulatory variants. Nucleic Acids Res 45:2307-2317.

Li W, Notani D, and Rosenfeld MG (2016) Enhancers as non-coding RNA transcription units: recent insights and future perspectives. Nat Rev Genet 17:207-223.

Lieberman-Aiden E, van Berkum NL, Williams L, Imakaev M, Ragoczy T, Telling A, Amit I, Lajoie BR, Sabo PJ, Dorschner MO, et al. (2009) Comprehensive mapping of long-range interactions reveals folding principles of the human genome. Science 326:289-293.

Liu S, Chen H, Ronquist S, Seaman L, Ceglia N, Meixner W, Chen PY, Higgins G, Baldi P, Smale S, et al. (2018) Genome architecture mediates transcriptional control of human myogenic reprogramming. iScience 6:232-246.

Liu S, Chen H, Ronquist S, Seaman L, Ceglia N, Meixner W, Muir LA, Chen PY Higgins GA, Baldi P, et al. (2017) Genome architecture leads a bifurcation in cell identity. bioRxiv Available from: 10.1101/151555.

Luders E, Kurth F, Toga AW, Narr KL, and Gaser C (2013) Meditation effects within the hippocampal complex revealed by voxel-based morphometry and cytoarchitectonic probabilistic mapping. Front Psychol 4:398 Available from: 10.3389/fpsyg. 2013.00398.

Luna A, Babur Ö, Aksoy BA, Demir E, and Sander C (2016) PaxtoolsR: pathway analysis in R using Pathway Commons. Bioinformatics 32:1262-1264.

Luo C and Ecker JR (2015) Epigenetics. Exceptional epigenetics in the brain. Science 348:1094-1095.

Lupiáñez DG, Kraft K, Heinrich V, Krawitz P, Brancati F, Klopocki E, Horn D, Kayserili H, Opitz JM, Laxova R, et al. (2015) Disruptions of topological chromatin domains cause pathogenic rewiring of gene-enhancer interactions. Cell 161: $1012-1025$

Lyst MJ, Nan X, and Stancheva I (2006) Regulation of MBD1-mediated transcriptional repression by SUMO and PIAS proteins. EMBO J 25 (22):5317-5328.

Mashtalir N, D'Avino AR, Michel BC, Luo J, Pan J, Otto JE, Zullow HJ, McKenzie ZM, Kubiak RL, St Pierre R, et al. (2018) Modular organization and assembly of SWI/SNF family chromatin remodeling complexes. Cell 175:1272-1288.e20.

Matharu N and Ahituv N (2015) Minor loops in major folds: enhancer-promoter looping, chromatin restructuring, and their association with transcriptional regulation and disease. PLoS Genet 11:e1005640 Available from: 10.1371/journal.pgen. 1005640 .

Mathur R, Alver BH, San Roman AK, Wilson BG, Wang X, Agoston AT, Park PJ, Shivdasani RA, and Roberts CW (2017) ARID1A loss impairs enhancer-mediated gene regulation and drives colon cancer in mice. Nat Genet 49:296-302.

Maurano MT, Humbert R, Rynes E, Thurman RE, Haugen E, Wang H, Reynolds AP, Sandstrom R, Qu H, Brody J, et al. (2012) Systematic localization of common disease-associated variation in regulatory DNA. Science 337:1190-1195.

Mehrmann C and Karmacharya R (2013) Principles and neurobiological correlates of concentrative, diffuse, and insight meditation. Harv Rev Psychiatry 21:205-218.

Meng Q, Wang K, Brunetti T, Xia Y, Jiao C, Dai R, Fitzgerald D, Thomas A, Jay L, Eckart H, et al. (2018) The DGCR5 long noncoding RNA may regulate expression of several schizophrenia-related genes. Sci Transl Med 10:eaat6912 Available from 10.1126/scitranslmed.aat6912.

Miller BR and Hen R (2015) The current state of the neurogenic theory of depression and anxiety. Curr Opin Neurobiol 30:51-58.

Nikolian VC, Dennahy IS, Higgins GA, Williams AM, Weykamp M, Georgoff PE, Eidy $\mathrm{H}$, Ghandour $\mathrm{MH}$, Chang $\mathrm{P}$, and Alam HB (2018) Transcriptomic changes following valproic acid treatment promote neurogenesis and minimize secondary brain injury. J Trauma Acute Care Surg 84:459-465.

Niu W, Zang T, Zou Y, Fang S, Smith DK, Bachoo R, and Zhang CL (2013) In vivo reprogramming of astrocytes to neuroblasts in the adult brain. Nat Cell Biol 15: $1164-1175$.

Onengut-Gumuscu S, Chen WM, Burren O, Cooper NJ, Quinlan AR, Mychaleckyj JC, Farber E, Bonnie JK, Szpak M, Schofield E, et al.; Type 1 Diabetes Genetics Consortium (2015) Fine mapping of type 1 diabetes susceptibility loci and evidence for colocalization of causal variants with lymphoid gene enhancers. Nat Genet 47: 381-386.

Ou HD, Phan S, Deerinck TJ, Thor A, Ellisman MH, and O'Shea CC (2017) ChromEMT: visualizing $3 \mathrm{D}$ chromatin structure and compaction in interphase and mitotic cells. Science 357:eaag0025 Available from: 10.1126/science. aag0025.

Pohodich AE and Zoghbi HY (2015) Rett syndrome: disruption of epigenetic control of postnatal neurological functions. Hum Mol Genet 24 (R1):R10-R16.

Pope BD, Ryba T, Dileep V, Yue F, Wu W, Denas O, Vera DL, Wang Y, Hansen RS, Canfield TK, et al. (2014) Topologically associating domains are stable units of replication-timing regulation. Nature 515:402-405.

Pulice JL and Kadoch C (2016) Composition and function of mammalian SWI/SNF chromatin remodeling complexes in human disease. Cold Spring Harb Symp Quant Biol 81:53-60.

Quang D and Xie X (2016) DanQ: a hybrid convolutional and recurrent deep neural network for quantifying the function of DNA sequences. Nucleic Acids Res 44:e107 Available from: 10.1093/nar/gkw226.

Rajapakse I and Smale S (2017) Emergence of function from coordinated cells in a tissue. Proc Natl Acad Sci USA 114:1462-1467.

Rajarajan P, Borrman T, Liao W, Schrode N, Flaherty E, Casiño C, Powell S, Yashaswini C, LaMarca EA, Kassim B, et al. (2018) Neuron-specific signatures in the chromosomal connectome associated with schizophrenia risk. Science 362: eaat4311 Available from: 10.1126/science.aat4311.

Rao SS, Huntley MH, Durand NC, Stamenova EK, Bochkov ID, Robinson JT, Sanborn AL, Machol I, Omer AD, Lander ES, et al. (2014) A 3D map of the human genome at kilobase resolution reveals principles of chromatin looping. Cell 159: $1665-1680$

Rhie SK, Schreiner S, Witt H, Armoskus C, Lay FD, Camarena A, Spitsyna VN, Guo Y, Berman BP, Evgrafov OV, et al. (2018) Using 3D epigenomic maps of primary olfactory neuronal cells from living individuals to understand gene regulation. $S c$ Adv 4:eaav8550 Available from: 10.1126/sciadv.aav8550.

Rizvi NF and Smith GF (2017) RNA as a small molecule druggable target. Bioorg Med Chem Lett 27:5083-5088.

Ronan JL, Wu W, and Crabtree GR (2013) From neural development to cognition: unexpected roles for chromatin. Nat Rev Genet 14:347-359.

Safe S, Abbruzzese J, Abdelrahim M, and Hedrick E (2018) Specificity protein transcription factors and cancer: opportunities for drug development. Cancer Prev Res (Phila) 11:371-382.

Santarelli L, Saxe M, Gross C, Surget A, Battaglia F, Dulawa S, Weisstaub N, Lee J, Duman R, Arancio O, et al. (2003) Requirement of hippocampal neurogenesis for the behavioral effects of antidepressants. Science 301:805-809.

Sexton T and Cavalli G (2015) The role of chromosome domains in shaping the functional genome. Cell 160:1049-1059.

Sheridan C (2017) CRISPR therapeutics push into human testing. Nat Biotechnol 35: 3-5.

Sievers QL, Petzold G, Bunker RD, Renneville A, Słabicki M, Liddicoat BJ, Abdulrahman W, Mikkelsen T, Ebert BL, and Thomä NH (2018) Defining the human $\mathrm{C} 2 \mathrm{H} 2$ zinc finger degrome targeted by thalidomide analogs through CRBN. Science 362:eaat0572 Available from: 10.1126/science.aat0572.

Snyder JS (2019) Recalibrating the relevance of adult neurogenesis. Trends Neurosci 42:164-178 Available from: 10.1016/j.tins.2018.12.001.

Sokpor G, Castro-Hernandez R, Rosenbusch J, Staiger JF, and Tuoc T (2018) ATP dependent chromatin remodeling during cortical neurogenesis. Front Neurosci 12 226.

Staahl BT and Crabtree GR (2013) Creating a neural specific chromatin landscape by npBAF and nBAF complexes. Curr Opin Neurobiol 23:903-913.

Stephens AD, Banigan EJ, Adam SA, Goldman RD, and Marko JF (2017) Chromatin and lamin A determine two different mechanical response regimes of the cell nucleus. Mol Biol Cell 28:1984-1996.

Stephens AD, Liu PZ, Kandula V, Chen H, Almassalha LM, Backman V, O'Halloran T, Adam SA, Goldman RD, Banigan EJ, et al. (2018) Physicochemical mechanotransduction alters nuclear shape and mechanics via heterochromatin formation bioRxiv Available from: 10.1101/423442.

Stricker SH, Köferle A, and Beck S (2017) From profiles to function in epigenomics. Nat Rev Genet 18:51-66.

Stunnenberg HG and Hirst M; International Human Epigenome Consortium (2016) The International Human Epigenome Consortium: a blueprint for scientific collaboration and discovery [published correction appears in Cell (2016) 167:1897] Cell 167:1145-1149.

Su Z, Niu W, Liu ML, Zou Y, and Zhang CL (2014) In vivo conversion of astrocytes to neurons in the injured adult spinal cord. Nat Commun 5:3338.

Sun J, Zhou L, Emerson DJ, Gilgenast TG, Titus K, Beagan JA, and Phillips-Cremins JE (2017) Genetic drivers of repeat expansion disorders localize to 3-D chromatin domain boundaries, bioRxiv Available from: 10.1101/191213.

The Gene Ontology Consortium (2019) The Gene Ontology Resource: 20 years and still GOing strong. Nucleic Acids Res 47 (D1):D330-D338.

Tjong H, Li W, Kalhor R, Dai C, Hao S, Gong K, Zhou Y, Li H, Zhou XJ, Le Gros MA et al. (2016) Population-based 3D genome structure analysis reveals driving forces in spatial genome organization. Proc Natl Acad Sci USA 113:E1663-E1672.

Van Bortle K, Nichols MH, Li L, Ong CT, Takenaka N, Qin ZS, and Corces VG (2014) Insulator function and topological domain border strength scale with architectura protein occupancy. Genome Biol 15:R82.

van Praag H, Schinder AF, Christie BR, Toni N, Palmer TD, and Gage FH (2002) Functional neurogenesis in the adult hippocampus. Nature 415:1030-1034.

Vernimmen D and Bickmore WA (2015) The hierarchy of transcriptional activation from enhancer to promoter. Trends Genet 31:696-708.

Wadi L, Meyer M, Weiser J, Stein LD, and Reimand J (2016) Impact of outdated gene annotations on pathway enrichment analysis. Nat Methods 13:705-706.

Walker AK, Rivera PD, Wang Q, Chuang JC, Tran S, Osborne-Lawrence S, Estill SJ, Starwalt R, Huntington P, Morlock L, et al. (2015) The P7C3 class of neuroprotective 
compounds exerts antidepressant efficacy in mice by increasing hippocampal neurogenesis. Mol Psychiatry 20:500-508.

Walters MC, Fiering S, Eidemiller J, Magis W, Groudine M, and Martin DI (1995) Enhancers increase the probability but not the level of gene expression. Proc Natl Acad Sci USA 92:7125-7129.

Wang D, Liu S, Warrell J, Won H, Shi X, Navarro FCP, Clarke D, Gu M, Emani P, Yang YT, et al.; PsychENCODE Consortium (2018) Comprehensive functional genomic resource and integrative model for the human brain. Science 362:eaat8464 Available from: 10.1126/science.aat8464.

Wang JM, Singh C, Liu L, Irwin RW, Chen S, Chung EJ, Thompson RF, and Brinton RD (2010) Allopregnanolone reverses neurogenic and cognitive deficits in mouse model of Alzheimer's disease. Proc Natl Acad Sci USA 107:6498-6503.

Wang S, Su JH, Beliveau BJ, Bintu B, Moffitt JR, Wu CT, and Zhuang X (2016) Spatial organization of chromatin domains and compartments in single chromosomes. Science 353:598-602.

Waszak SM, Delaneau O, Gschwind AR, Kilpinen H, Raghav SK, Witwicki RM, Orioli A, Wiederkehr M, Panousis NI, Yurovsky A, et al. (2015) Population variation and genetic control of modular chromatin architecture in humans. Cell 162:1039-1050. Weintraub AS, Li CH, Zamudio AV, Sigova AA, Hannett NM, Day DS, Abraham BJ, Cohen MA, Nabet B, Buckley DL, et al. (2017) YY1 is a structural regulator of enhancer-promoter loops. Cell 171:1573-1588.e28.

Whalen S and Pollard KS (2019) Most chromatin interactions are not in linkage disequilibrium. Genome Res 29 (3):334-343.

Wu JI, Lessard J, Olave IA, Qiu Z, Ghosh A, Graef IA, and Crabtree GR (2007) Regulation of dendritic development by neuron-specific chromatin remodeling complexes. Neuron 56:94-108.
Yin JC, Zhang L, Ma NX, Wang Y, Lee G, Hou XY, Lei ZF, Zhang FY, Dong FP, Wu GY, et al (2019) Chemical conversion of human fetal astrocytes into neurons through modulation of multiple signaling pathways. Stem Cell Reports 12:488-501 Available from: 10.1016/j.stemcr.2019.01.003

Yoon KJ, Vissers C, Ming GL, and Song H (2018) Epigenetics and epitranscriptomics in temporal patterning of cortical neural progenitor competence. J Cell Biol 217:1901-1914. Young RA (2011) Control of the embryonic stem cell state. Cell 144:940-954.

Yu M and Ren B (2017) The three-dimensional organization of mammalian genomes Annu Rev Cell Dev Biol 33:265-289.

Zeng J, Bauer DE, Wu Y, Roscoe BP, Liu P, Yao Q, Lazzarrotto C, Clement MK, Cole MA, Luk K, et al. (2018) Highly efficient therapeutic gene editing of BCL11A enhancer in human hematopoietic stem cells from $\beta$-Hemoglobinopathy patients for fetal hemoglobin induction. Blood 132:3482.

Zhang R, Lahens NF, Ballance HI, Hughes ME, and Hogenesch JB (2014) A circadian gene expression atlas in mammals: implications for biology and medicine. Proc Natl Acad Sci USA 111:16219-16224.

Zhang Y, Wong CH, Birnbaum RY, Li G, Favaro R, Ngan CY, Lim J, Tai E, Poh HM, Wong E, et al. (2013) Chromatin connectivity maps reveal dynamic promoterenhancer long-range associations. Nature 504:306-310.

Zhou M, Hu Z, Qiu L, Zhou T, Feng M, Hu Q, Zeng B, Li Z, Sun Q, Wu Y, et al. (2018) Seamless genetic conversion of SMN2 to SMN1 via CRISPR/Cpf1 and singlestranded oligodeoxynucleotides in spinal muscular atrophy patient-specific induced pluripotent stem cells. Hum Gene Ther 29:1252-1263.

Zhu Y, Elemento O, Pathak J, and Wang F (2018) Drug knowledge bases and their applications in biomedical informatics research. Brief Bioinformatics, doi: 10.1093/ bib/bbx169. 